\title{
Chitosan derivatives modified solid lipid nanoparticles prolonged Rhodojaponin-III active time and enhanced the safety and multimodal analgesic effects in vivo
}

\section{Qingyun Yang}

Shanghai University of Traditional Chinese Medicine

Jian Yang

Shanghai University of Traditional Chinese Medicine

\section{Shuigeng Sun}

Shanghai University of Traditional Chinese Medicine Jingyi Zhao

Shanghai University of Traditional Chinese Medicine

Shuang Liang

Shanghai University of Traditional Chinese Medicine

Yi Feng

Shanghai University of Traditional Chinese Medicine

Minchen Liu

Shanghai University of Traditional Chinese Medicine

Zhang JiQuan ( $\nabla$ jqzhang@shutcm.edu.cn )

Shanghai University of Traditional Chinese Medicine

\section{Research Article}

Keywords: Rhodojaponin-III, multimodal antinociceptive, oral administration, solid lipid nanoparticles, hydroxypropyl trimethyl ammonium chloride chitosan, safety evaluation, pharmacokinetic

Posted Date: January 17th, 2022

DOI: https://doi.org/10.21203/rs.3.rs-1234562/v1

License: (1) This work is licensed under a Creative Commons Attribution 4.0 International License. Read Full License 


\section{Abstract \\ Background}

Rhodojaponin III (RJ-III), a bioactive diterpene, is a characteristic component of Rhododendron molle G. Don (Ericaceae), a potent analgesia in traditional Chinese medicine with thousands of years of clinical applications. However, its clinical use is limited by its acute toxicity and poor pharmacokinetic profile. To reduce such limitations, we incorporated RJ-III into the colloidal drug delivery system of hydroxypropyl trimethyl ammonium chloride chitosan (HACC) modified solid lipid nanoparticles (SLNs) to improve its sustained release and analgesic properties in vivo for oral delivery.

\section{Results}

The optimized RJ-III@HACC-SLNs were close to spherical, approximately $134 \mathrm{~nm}$ in size, with a positive zeta potential. In vitro experiments showed that RJ-III@HACC-SLNs were stable in the simulated gastric fluid, and were prolonged release in PBS $(\mathrm{pH}=6.8)$. Pharmacokinetics results showed that after intragastric administration in mice, the relative bioavailability of RJ-III@HACC-SLNs was 87.9\%, the peak time, half-time, and mean retention time of RJ-III@HACC-SLNs were significantly improved.

Pharmacodynamic studies revealed that RJ-III@HACC-SLNs markedly reduced the acetic acid, hot, and formalin-induced nociceptive responses in mice $(P<0.001)$, and significantly increased the analgesic time $(P<0.01)$. Moreover, RJ-III@HACC-SLNs not only showed good biocompatibility with Caco-2 cells in vitro, but its $\mathrm{LD}_{50}$ value was also increased by 1.8 -fold compared to RJ-III in vivo.

\section{Conclusions}

This study indicated that RJ-III@HACC-SLNs could exhibit certain toxicity-attenuating and effectivenessenhancing effects by improving pharmacokinetic characteristics of the RJ-III, which could be a new strategy for intragastric delivery and analgesic treatment of RJ-III and HACC-modified SLNs, and provide a dosage form reference for the further study of RJ-III.

\section{Background}

Pain, an unpleasant emotional and sensory experience [1, 2], is the most common symptom for seeking medical care $[3,4]$. With regards to disability, prevalence and economic burden, unrelieved pain is a major human health concern $[5,6]$. Estimates suggested that the age-standardized prevalence of chronic pain conditions was $12 \sim 25 \%$ in developed countries and $34 \sim 41 \%$ in developing countries $[7,8]$. The available pain management strategies heavily rely on agents with analgesic properties, such as opioids, non-steroidal anti-inflammatory drugs, antidepressants, and anticonvulsant agents [4]. These analgesic drugs are clinically extensively used, however, only about one in four of individuals with pain achieve satisfactory relief [9]. Moreover, these drugs are associated with harmful side effects, poor tolerability, 
long-term safety concerns as well as the potential for abuse, and the inconvenience of use [9]. Therefore, new non-opioids analgesic agents with a high efficacy are important and necessary.

For thousands of years, Rhododendron molle G. Don has been clinically used to treat pain in China [10]. Rhodojaponin III (RJ-III), a grayanane-type diterpenoid, of the natural products isolated from this herb, showed extensive biological activities [11-13] such as antinociceptive effects [14], anti-rheumatoid arthritis [15], lowering the blood pressure [16], slowing the heart rate [16], and inhibiting inflammatory response [17]. Remarkably, compared to morphine, RJ-III exhibited more efficacy in both acute as well as inflammatory pain models. In diabetic neuropathic pain models, its potency was 100 -fold that of the firstline drug gabapentin [14]. In addition, naloxone, a morphine antagonist, did not exert significant antagonism on analgesic effects of RJ-III in an acetic acid-mediated writhing test [14]. Based on these reports, RJ-III is a potential non-opioid analgesic for pain management. However, RJ-III showed severe acute toxicity with $\mathrm{LD}_{50}$ of $7.609 \mathrm{mg} / \mathrm{kg}$ in mice when it was orally administered [18]. We studied the pharmacokinetic properties of RJ-III in mice, and the results showed that RJ-III the $T_{\max }$ was $0.08 \mathrm{~h}, \mathrm{t}_{1 / 2}$ was $0.76 \mathrm{~h}$, and oral absolute bioavailability was $73.6 \%$, which showed RJ-III possessed characteristics with rapid absorption, rapid elimination, and good oral bioavailability [19]. These results suggested that drug delivery system with sustained-release capability can provide good pharmacological effects and decrease acute toxicity of RJ-III by prolonging the action time and reducing fluctuation of plasma concentration.

Nowadays, colloidal drug delivery systems have enhanced the oral pharmacokinetic characteristics of therapeutic agents and their bioavailability $[20,21]$. In early 1990s, solid lipid nanoparticles (SLNs), colloidal drug delivery systems, were introduced. They range from 30 to $1,000 \mathrm{~nm}$ in size and are prepared from solid lipids and stabilized by surfactants [20-22]. SLNs have received more attention than other nano-delivery systems oral administration including controlled drug release by the hindrance of solid lipid shells, enhanced absorption through the lymphatic delivery through microfold cells, and extensive drug payload characteristics based on loaded both lipophilic and hydrophilic drugs [20-22]. The conventional SLNs are associated with various advantages, however, intragastric administration of bioactive compounds is challenging, that is, burst release of compounds in the stomach at a $\mathrm{pH}$ of approximately $1 \sim 3$, which is low [23-26]. To promote the delivery of bioactive compounds and to inhibit higher release in the stomach, various surface modifications are performed on SLNs [23-26]. The electropositive water-soluble chitosan derivative, hydroxypropyl trimethyl ammonium chloride chitosan (HACC) [27], can potentially be used in various fields e.g. tumor therapy [28] and drug delivery [27, 29] since its quaternized cationic nature allows strong electrostatic interactions with negatively charges [27-30]. A recent study showed that HACC was successfully modified solid lipid nanoparticles loading docetaxel to enhance gastrointestinal stability and intragastric bioavailability [31]. However, the application of HACCmodified SLN both in loading RJ-III and in analgesia has not been reported.

In this study, RJ-III was firstly incorporated into SLNs modified by HACC to obtain the RJ-III@HACC-SLNs to better exert the advantages of oral administration such as the absence of pain sensations, easy selfadministration, as well as exceptional patient compliance [32,33]. Furthermore, the carrier materials and 
modification process were improved to guarantee stable delivery of RJ-IIl in gastrointestinal environments and sustained release. Then, pharmacokinetic characteristics of RJ-II@ @HACC-SLNs were investigated after intragastric administration in mice to evaluate the ability of HACC-SLN to improve half-life and decrease plasma fluctuation. Based on that, the anti-nociceptive effects of RJ-III@HACC-SLNs were examined by multimodal which the acetic acid-mediated writhing and the hot-plate test simulates acute pain models, the formalin test simulates acute as well as persistent inflammatory pain. The safety of RJIII@HACC-SLNs was investigated by cytotoxicity of Caco-2 cells in vitro and acute toxicity test on mice in vivo. These results inform clinical applications of HACC-modified SLNs and analgesic development of RJ-III. Meanwhile, these results will help evaluate whether the HACC-modified SLNs with protonation in acidic conditions can maintain the stability of RJ-III-containing SLNs and thus prolong the active time of $\mathrm{RJ}-\mathrm{III}$ in vivo.

\section{Results}

\subsection{Prepared and optimization of RJ-III@HACC-SLNs}

RJ-III@SLNs were successfully prepared by emulsification-diffusion [34]. Then, the RJ-III@HACC-SLNs were obtained as recognized as a clear solution by electrostatic adsorption between RJ-III@SLNs and HACC solution, as shown in Figure 1. In the further study, variables such as the volume ratio of HACC liquid $\left(\mathrm{V}_{\mathrm{H}}\right)$ to $\mathrm{SLNs}$ suspension $\left(\mathrm{V}_{\mathrm{S}}\right)$, stirring time, and solid lipid that influenced the particle size, zeta potential, as well as the encapsulation efficiency (EE) of RJ-III@HACC-SLNs were identified, and single factor screening conducted to investigate the modified process and the core lipid. Previous studies have shown that the nanoparticles considered as members of the nanotoxicological classification system classes I with particle size of above $100 \mathrm{~nm}$ and made of biodegradable materials [35], the zeta potential $\pm 15 \mathrm{mV}$ or higher ensures adequate repulsion of the nearby nanoparticles in the suspension $[34,36]$. Therefore, the optimization principle of RJ-II!HACC-SLNs was to select the option with the best EE when the particle size was above $100 \mathrm{~nm}$ while the zeta potential was higher than $15 \mathrm{mV}$.

As shown in Figures 2A, 2B, 2C, in the modification process, the $E E$, zeta potential and particle size of RJIII@HACC-SLNs were affected by the different volume ratios of $V_{H}$ to $V_{S}$ ). In particle size, it can be concluded that particle size decreases with the decrease of volume ratios of $V_{H}$ to $V_{S}$. Further analysis revealed that the 2:1 group was significantly better than the 4:1 group and the 1:1 group in EE and zeta potential. Therefore, 2:1 was chosen as the ideal volume ratio of $V_{H}$ to $V_{S}$. Furthermore, as shown in Figures 2D, 2E, 2F, in stirring time, we inferred that increasing the time decreased the lower EE and higher zeta potential of nanoparticles. In terms of particle size, there was a significant difference between the $1 \mathrm{~h}$ group and the $2 h$ group $(P<0.01)$ but no significant difference from the $4 h$ group $(P>0.05)$. Meanwhile, the zeta potential of RJ-III@HACC-SLNs were above $15 \mathrm{mV}$ within $1 \sim 4 \mathrm{~h}$, but the zeta potential of $2 \mathrm{~h}$ and $4 \mathrm{~h}$ groups was markedly higher relative to that of $1 \mathrm{~h}$ group $(P<0.001, P<0.001)$. However, in terms of $\mathrm{EE}$, the $1 \mathrm{~h}$ group was markedly higher than those of the $2 \mathrm{~h}$ and $4 \mathrm{~h}$ groups $(P<0.001)$. Therefore, the 
preparation process for modified RJ-III@SLNs with a volume ratio of 2:1 and a stirring time of $1 \mathrm{~h}$ was determined to select the optimal RJ-II!HACC-SLNs.

One solid lipid was identified as a lipid matrix in five commonly used oral delivery and biodegradable solid lipids of Glycerol monostearate (GM), glyceryl tristearate (GT), stearic acid (SA), Precirol ATO 5 (ATO 5), as well as Compritol 888 ATO (888 ATO) (Figure 3) [22, 26]. Before modification, particle sizes of RJIII@SLNs increased with molecular weights of the different lipids, and all the zeta potentials of RJIII@SLNs were negative potential, and the EE of RJ-III@SLNs varied due to the properties of the different lipids. The SA was not subjected to further investigation because of its low $\mathrm{EE}$ and absolute value of potential. However, during the modification process, flocculation occurred in RJ-III@SLNs based on 888 ATO, which had the highest EE, therefore 888 ATO was excluded. After modification, particle size of HACCmodified SLNs was larger relative to those of unmodified SLNs, zeta potential of SLNs changed from negative potential to positive potential, implying that HACC was adsorbed onto drug-loaded SLNs through non-covalent bonds. Furthermore, the RJ-III@HACC-SLNs based on GM possessed a smaller particle size, higher zeta potential and EE than the others. What's more, many original publications had shown that SLNs based on GM could enhance bioavailability and prolonged circulation time [26]. Therefore, GM was selected as the core lipid.

The optimized RJ-III@HACC-SLNs exhibited a light blue opalescence (Figure 4A), particle size of (134.47 \pm 2.73) $\mathrm{nm}$, zeta potential of $(18.72 \pm 1.15) \mathrm{mV}$, and $\mathrm{EE}$ of $(73.80 \pm 8.86) \%$ (Figure $4 \mathrm{~B})$. It was subjected to further physicochemical characterization, pharmacokinetics, antinociceptive, and safety studies.

\subsection{Structural characterization of RJ-III@HACC-SLNs}

The data shown in Figure 4B demonstrate that RJ-III@HACC-SLNs nearly acquired a spherical shape. XRD is important for evaluating changes in RJ-III crystallinity or its precipitation abilities in amorphous forms and presented in Figure 4C. The XRD pattern of RJ-III reveals the crystalline characteristic of the drug. Sharp crystalline peaks at $2 \theta$ scattered angles between $5^{\circ}$ and $17^{\circ}$ disappeared in RJ-III@HACC-SLNs and RJ-III@SLNs but instead showed two mountain peaks at $19^{\circ}$ and $23^{\circ}$, suggesting that the disordered crystalline state of RJ-III entrapped by the core of SLNs. The surface characterization of prepared SLNs was further evaluated by using FT-IR. In Figure 4D, the FT-IR spectra revealed the disappearance of the bimodal peak near 3407-3638 $\mathrm{cm}^{-1}$ which belongs to hydroxyl group [-OH] of RJ-III, and the peaks in 800-1500 $\mathrm{cm}^{-1}$ of RJ-III significantly decreased in RJ-III@SLNs. After coating the HACC, the peak appearing at $1481 \mathrm{~cm}^{-1}$ was due to $\left[-\mathrm{CH}_{3}\right]$ of quarternary ammonium group skeleton stretching vibration, which supported the HACC coating on the surface of RJ-III@SLNs [28].

\subsection{In vitro stability and release of RJ-II!@HACC-SLNs}

The oral therapeutics delivery strategy developed improved the pharmacological effects and decreased acute toxicity of RJ-III by prolonging the action time and reducing fluctuation of plasma concentration. Therefore, in vitro stability as well as release of nanoparticles are essential for investigating the dosage form performance. Figure 5A shows a strong stability of RJ-III@HACC-SLNs when compared to RJ- 
III@SLN. The EE of RJ-III@HACC-SLNs was no significant decrease $(P>0.05)$, that RJ-III@SLNs was an extremely significant decrease $(P<0.001)$, during $3 \mathrm{~h}$ incubated in SGF. The above changes in nanoparticle properties suggest the better stability of HACC modification agents in artificial gastric fluids, possibly because HACC prevents the amino and hydroxy groups of chitosan from generating hydrogen bonds, improving water solubility and positive activity for protonation under acidic conditions, and protecting nanoparticle stability $[27,29]$.

The in vitro release of RJ-III@HACC-SLNs was investigated at $37^{\circ} \mathrm{C}$ under pH 6.8 PBS solutions. As shown in Figure 5B, the RJ-III solution was $95 \%$ within $24 \mathrm{~h}$, indicating rapid diffusion of RJ-III, while the release rate of RJ-III encapsulated in SLNs or HACC-SLNs was relatively gentle indicating that the nanocarriers showed some resistance to the release of RJ-III. Further, the RJ-III@SLNs exhibited a higher RJ-III release rate than RJ-III@HACC-SLNs, while the cumulative RJ-III release of RJ-II@@HACC-SLNs was higher than RJ-III@SLNs. In the first 2 h, over 33\% of the drug had been released from RJ-III@SLN, while $15 \%$ of the drug had been released from RJ-III@HACC-SLNs. Then, the release was sustained for up to 24 h, with in a total release of $41 \%$ or $56 \%$, respectively. The distinct release profiles suggested that the HACC coated on the surfaces of the RJ-III@SLNs could sustain release by effectively suppressing drug release rate through adsorption interactions between HACC and SLNs. Meanwhile, the free drug is important to exert immediate antinociceptive when treatment with RJ-III@HACC-SLNs, which indicated RJ-III@HACCSLNs may exert rapid and lasting analgesic effects in vivo.

\subsection{Pharmacokinetic study}

The pharmacokinetic characteristics were performed using various formulations: RJ-III solution and RJIII@HACC-SLNs were tested using 0.2 mg/kg administered in mice. RJ-II@SLNs was not selected for the experiments because of their instability and fast release. Figure 6 and Table 1 respectively show the plasma concentration-time curves of RJ-III and mean pharmacokinetic parameters. Wide variabilities in PK parameters were noted between the various RJ-III formulations. The RJ-III solution was the control in this assay. 
Table 1

Pharmacokinetic parameters of RJ-囚, HACC@RJ-囚-SLNs after oral administration $(0.2 \mathrm{mg} / \mathrm{kg})$ in mice (Mean, $n=6$ )

\begin{tabular}{|lll|}
\hline Parameters & RJ-III & RJ-III@HACC-SLNs \\
\hline $\mathrm{t}_{1 / 2}(\mathrm{~h})$ & 1.37 & 4.50 \\
\hline $\mathrm{T}_{\text {max }}(\mathrm{h})$ & 0.08 & 0.50 \\
\hline $\mathrm{C}_{\text {max }}(\mathrm{ng} / \mathrm{L})$ & 82.0 & 56.2 \\
\hline $\mathrm{AUC}_{0-\mathrm{t}}(\mathrm{ng} \cdot \mathrm{h} / \mathrm{L})$ & 122.6 & 107.8 \\
$\mathrm{MRT}_{0-\mathrm{t}}(\mathrm{h})$ & 1.48 & 2.15 \\
\hline $\mathrm{CL} / \mathrm{F}(\mathrm{L} / \mathrm{h} / \mathrm{kg})$ & 1.95 & 2.23 \\
\hline $\begin{array}{l}\mathrm{AUC} \text {, area under the curve; } \mathrm{C}_{\text {max }} \text {, peak concentration; MRT, mean retention time; CL/F, clearance rate; } \\
\mathrm{t}_{1 / 2} \text {, half-life; } \mathrm{T}_{\text {max }} \text {, peak time. }\end{array}$ & \\
\hline
\end{tabular}

The RJ-III solution resulted in $\mathrm{T}_{\max }$ at $0.083 \mathrm{~h}$ and $\mathrm{t}_{1 / 2}$ at $1.37 \mathrm{~h}$, which illustrated oral bioavailability problems with rapid absorptions and RJ-III elimination. In contrast, the RJ-III@HACC-SLNs yielded a $\mathrm{C}_{\max }$ of $56.22 \pm 12.72 \mathrm{ng} / \mathrm{mL}$ at 0.5 hours post-administration, and a longer $t_{1 / 2}$ and MRT, implying that in this form, RJ-III has a long drug residence and active time. Furthermore, relative bioavailability of RJIII@HACC-SLNs was calculated at 87.9\%, showing that RJ-III@HACC-SLNs maintain good oral absorption while prolonging RJ-III release in vivo. These results lay the foundation for further in vivo multimodal analgesic pharmacodynamic studies.

\subsection{Multimodal analgesia of RJ-III@HACC-SLNs}

We evaluated in vivo antinociceptive effects of RJ-III@HACC-SLNs, therefore different stimuli e.g. hotplate, acetic acid, as well as formalin-induced nociception selected as pain models. According to preliminary results, $0.1 \mathrm{mg} / \mathrm{kg}$ RJ-III was selected as the optimal dose in the acetic acid-induced writhing and formalin tests, $0.2 \mathrm{mg} / \mathrm{kg} \mathrm{RJ}$-III was chosen as the dose in the hot-plate test, to inhibit the occurrence of toxic effects, $300 \mathrm{mg} / \mathrm{kg}$ aspirin was selected as the positive drug group.

In the first series of experiments, the acetic acid-induced writhing test, a sensitive, predictive acute pain animal model $[37,38]$ was used to assess antinociceptive effects of RJ-III@HACC-SLNs. Figure 7A reveals that relative to the normal saline group at administration $15 \mathrm{~min}$ and $45 \mathrm{~min}$, there were marked differences in the number of writhes among the RJ-III group $(P<0.001, P<0.001)$, the RJ-III@HACC-SLNs group $(P<0.001, P<0.001)$, and the aspirin group $(P<0.001, P<0.01)$, indicating that group RJ-III, RJIII@HACC-SLNs, and aspirin, exerted analgesic effects within 45 min. Furthermore, the RJ-III@HACC-SLNs group exhibited a more lasting analgesic effect compared to groups RJ-III and aspirin, which RJIII@HACC-SLNs group showed no marked differences in the number of writhes between 15min and 45min $(P>0.05)$, while groups RJ-III and aspirin showed statistically increases in number of writhes $(P<0.001$, 
$P<0.01)$. Remarkably, the RJ-III@HACC-SLNs group showed a greater analgesic efficacy compared to groups RJ-III and aspirin after administration $45 \mathrm{~min}$, which there is a significant difference in writhing number of RJ-III@HACC-SLNs contained $0.10 \mathrm{mg} / \mathrm{kg}$ RJ-III compared with the $0.10 \mathrm{mg} / \mathrm{kg} \mathrm{RJ}$-III group and the $300 \mathrm{mg} / \mathrm{kg}$ aspirin group $(P<0.05, P<0.01)$.

Central antinociceptive effects of RJ-III@HACC-SLNs were assessed in the hot-plate test, using classic acute pain models that record responses to thermal stimuli $[39,40]$. As shown in Figure 7B, after administration of $15 \mathrm{~min}, 300 \mathrm{mg} / \mathrm{kg}$ aspirin and $0.2 \mathrm{mg} / \mathrm{kg}$ RJ-III increased the latency time compared to the basic pain threshold of pre-treatment $(P<0.05, P<0.05)$. In contrast, the RJ-III@HACC-SLNs showed superior potency at doses approximately 1500 -fold lower than aspirin $(P<0.001)$. After administration of 45 min, RJ-III, RJ-III@HACC-SLNs maintained its antinociception effects relative to the basic pain threshold of the pre-treatment group $(P<0.05, P<0.001)$. Moreover, antinociceptive was more effective of RJ-III@HACC-SLNs compared with RJ-III after $45 \mathrm{~min}(P<0.01)$. Notably, the aspirin group showed no significant analgesic effect after administration 45 minutes $(P>0.05)$.

To investigate antinociceptive characteristics, RJ-III and RJ-III@HACC-SLNs were evaluated in the formalin test $[38,41]$. Responses in phase I correlated with acute neurogenic pain, which was largely due to direct stimulation of nociceptors $[38,41]$. Contrastingly, the mechanisms involved in phase II responses were highly complex, involving inflammatory processes accompanied by spontaneous primary afferent neuronal activities as well as central alterations of pain processing [38, 41]. Figures 7C and 7D show that within 15 min of administration, the non-steroidal anti-inflammatory drug aspirin suppressed behavioral responses in phase II (the inflammatory phase) $(P<0.01)$, but had not effects on phase I responses $(P>$ 0.05) as previous studies [42]. By comparison, RJ-III and RJ-III@HACC-SLNs were active in both phases I and II $(P<0.01, P<0.001)$ within administration $15 \mathrm{~min}$. At this point, the analgesic effect of RJ-III in phase I and phase II was stronger than that of RJ-III@HACC-SLNs $(P<0.01, P<0.001)$. After administration for 45 min, RJ-III and RJ-III@HACC-SLNs still showed an analgesic effect in phases I and II, but RJ-III and RJ-III@HACC-SLNs showed a completely different analgesic trend, significantly enhanced in RJ-III@HACC-SLNs $(P<0.05)$ and significantly decreased in RJ-III $(P<0.001)$ when compared to the respective administration for $15 \mathrm{~min}$. Remarkably, post-treatment $45 \mathrm{~min}$, the analgesic effect of RJIII@HACC-SLNs in phase I and phase II was stronger than that of RJ-III $(P<0.01, P<0.01)$.

These data demonstrated that RJ-III@HACC-SLNs showed a durable and effectiveness at suppressing responses in physical or chemically induced acute and inflammatory pain, compared to RJ-III and aspirin.

\subsection{In vitro Cytotoxicity studies}

The study of cytotoxicity was done to elucidate on the biocompatibility of oral absorptions of HACC-RJIII@SLNs. The cytotoxic effect of the SLNs formulations, with and without RJ-III, against Caco-2 cells is given in Figure 8 . A cell viability of $>80 \%$ was considered non-toxic to cells [31]. As shown in Figure 8A, under the experimental conditions, the SLNs and HACC-SLNs without RJ-III, were noncytotoxic to the cell, even at doses of up to $500 \mu \mathrm{g} / \mathrm{mL}$, suggesting that SLNs and HACC-SLNs might be good carriers for RJ-III delivery. We further explored the effect of different concentrations of RJ-III on cytotoxicity caused by RJ- 
III@SLNs and RJ-III@HACC-SLNs. The cytotoxicity studies (Figure 8B) showed cell viability was over 90\% for 0 - $20 \mu \mathrm{g} / \mathrm{mL}$ RJ-III concentration for $24 \mathrm{~h}$. This indicates that HACC@RJ-囚-SLNs did not cause significant toxicity to Caco-2 cells across tested concentrations, which matches with previous reports [31], provided an experimental basis for the subsequent oral absorption mechanism research of HACC@RJ-凹SLNs.

\subsection{Acute toxicity}

To further evaluate the safety of RJ-III@HACC-SLNs, the acute lethal test, RJ-III, and RJ-III@HACC-SLNs were administered through single oral administration at increasing doses, and mortality was noted over the 7 days. Figure 9 and Table 2 show that the LD $_{50}$ of RJ-III and RJ-III@HACC-SLNs was 3.62 (2.96 4.29 , at a $95 \%$ confidence limit) and $6.42 \mathrm{mg} / \mathrm{kg}(5.18 \sim 7.66$, at a $95 \%$ confidence limit), respectively, indicating that the acute toxicity of RJ-III@HACC-SLNs was approximately $1 / 2$ of that of RJ-III, suggested HACC-modified SLNs reducing the acute toxicity of RJ-III, and indicated that RJ-IIIHACC-SLNs had sufficient safety when playing analgesic effect.

Table 2 Acute lethal effects of RJ-III and RJ-II!@HACC-SLNs after single intragastric administration in ICR mice $(n=8)$

\begin{tabular}{|c|c|c|c|}
\hline Treatments & 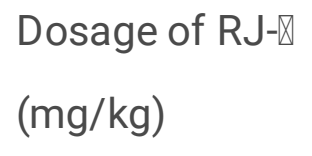 & $\begin{array}{l}\text { Mortality } \\
\text { (\%) }\end{array}$ & $\begin{array}{l}\mathrm{LD}_{50} \\
(\mathrm{mg} / \mathrm{kg})\end{array}$ \\
\hline \multirow[t]{5}{*}{ RJ- $\rrbracket$} & 1.711 & 0.0 & \multirow[t]{5}{*}{3.62} \\
\hline & 2.312 & 25.0 & \\
\hline & 3.125 & 37.5 & \\
\hline & 4.223 & 75.0 & \\
\hline & 5.707 & 87.5 & \\
\hline \multirow[t]{5}{*}{ RJ-III@HACC-SLNs } & 3.423 & 0.0 & \multirow[t]{5}{*}{6.42} \\
\hline & 4.625 & 37.5 & \\
\hline & 6.250 & 50.0 & \\
\hline & 8.446 & 75.0 & \\
\hline & 11.413 & 100.0 & \\
\hline
\end{tabular}

\section{Discussion}


With rising awareness, chronic pain has been defined as a disease in medicine and a global public health priority in the field of public health [7]. Pain impairs the quality of life and is associated with enormous societal economic losses $[5,6,43]$. It is estimated that per year, pain costs more than $\$ 100$ billion in direct healthcare costs and lost work time in the US $[5,6,43]$. Managing pain is a vast clinical challenge. The lack of powerful and non-opioids analgesics has contributed to the recent opioid abuse tragedy [9]. The urgency of the situation demands a major effort to identify new drugs for the treatment of pain.

With thousands of years of clinical use and good efficacy of relieve pain, traditional Chinese medicine may provide an opportunity for a rapid search for new analgesic agents. In China, 426 analgesic traditional drugs were recorded in the Chinese Pharmacopoeia alone, while also identified several monomeric compounds to serve as new analgesic compounds, including alkaloids, flavonoids, terpenoids, and coumarins, etc [44]. Among these compounds, RJ-III is one of the most potent active molecules to develop as an analgesic, but its development is hindered by its high acute toxicity [18] and rapid in vivo elimination [19]. It is key to further research that how to reduce toxicity and enhance the efficacy of such small molecule drugs. This paper provides a feasible dosage form for further analgesic development of RJ-III, and a new perspective for the application of HACC-modified SLNs in analgesic development. In this study, the sustained release of HACC-SLNs suppressed fluctuations in plasma levels of RJ-III, which in turn improved the efficacy of RJ-III analgesia and reduced acute toxicity of RJ-III.

In the preparation of RJ-III@HACC-SLNs, the coating with the HACC process and lipid were important in design formulation. Modified process should be selected based on rational particle size, zeta potential, and EE. Previous work showed that particle sizes of SLNs were markedly affected by volume ratios of $V_{S}$ to $V_{H}$ [31]. Considering the important role of the surface charge and $E E$ on stability and sustained release of nanoparticles, they were included in the observational index. The results from optimizing the modification process showed that the above two influencing factors also have significant effects on the EE and zeta potential of Surface-modified solid lipid nanoparticles containing RJ-III. RJ-III@HACC-SLNs were prepared using a combination of emulsification-diffusion method and optimized modified processes method, for lipid screening.

The ingredients of SLNs include emulsifier(s), solid lipid(s), and water [22]. The solid lipid, had a significant effect on EE and particle size of SLNs due to their different molecular weight and solubility [22]. They include triglycerides, hard fat types, steroids, fatty acids, and waxes [22]. In this study, we selected core lipids by comparing the EE and particle size of RJ-III@HACC-SLNs based on five commonly used solid lipids (GM, GT, SA, ATO 5, and 888 ATO). and finally, we decided to use GM as the core lipid. GM has a single fatty acid chain bonded to a glycerol backbone $[45,46]$, possesses amphiphilic nature, $[45,46]$ can self-assemble in water or oil into various mesophases, is extensively used in food as well as personal care products $[45,46]$. Herein RJ-III@HACC-SLNs based on GM had better physical characteristics, with the particle size of around $139 \mathrm{~nm}$ suggesting that it may be absorbed by intestinal epithelial cells and reach the circulatory system with an intact particle [47-49], the zeta potential of about $19 \mathrm{mV}$ indicating possible good stability and may more be important to drug absorption due to 
electrostatic adsorption between cell membranes and HACC-SLNs with the positive charge [47-49], and EE of almost $73 \%$ almost implying a potentially better slow-release effect.

For complex nanocarriers, in vitro stability and release testing are essential analytical tools to investigate the dosage form performance and release mechanism [50]. To select the suitable nano-formulation for in vivo study, RJ-II!@SLNs and RJ-III@HACC-SLNs have discussed particle size and EE in SGF and observed for drug release studies in PBS $(\mathrm{pH}=6.8)$. Studies revealed that HACC-modified SLNs significantly affected the stability of nanoparticles and the release of the drug, which might be due to the deprotonation of HACC under acidic conditions [27, 29, 31]. Therefore, RJ-III@HACC-SLNs was selected as the optimal formulation, and subsequent studies conducted on pharmacokinetic, antinociceptive, and safety, while the RJ-III@SLNs weren't further investigated because of their instability and fast release.

To evaluate the sustained-release capacity of RJ-III@HACC-SLNs, it is important to elucidate its pharmacokinetic properties. In this experiment, RJ-III overall presented the characteristics of high oral absorption rate and rapidly metabolized as our previous results [19]. After oral RJ-III administration in the form of HACC-SLNs, $T_{\max }$ and $t_{1 / 2}$ were delayed via endocytosis, reaching peak time at about $0.5 \mathrm{~h}$, reached the half-life time at approximately $4.50 \mathrm{~h}$. They were lower $\mathrm{C}_{\max }$ and longer MRT than that in the RJ-III group, suggesting that RJ-III@HACC-SLNs avoid the fluctuations in plasma levels and sustained release of RJ-III in vivo.

The analgesic effects of RJ-III@HACC-SLNs in mice were determined using the acetic acid writhing test and hot plate test as acute pain models, and formalin test as a model with both acute and persistent inflammatory pain [37-39]. Aspirin, a non-steroidal anti-inflammatory drug, is an effective, versatile medication for mild-to-moderate pain [51]. In this study, aspirin was the positive drug. After intragastric administration, RJ-III@HACC-SLNs showed a fast and durable effective analgesic effect in physical or chemically induced acute pain and chemically induced inflammatory pain, which may be attributed to the prolonged release of nanoparticles in vivo. The pro-inflammatory cytokines, including IL-1b, TNF-a, as well as IL-6 play an active role in pain [52-54], while according to the relevant studies, RJ-III exhibited a strong anti-inflammatory potential by suppressing pro-inflammatory cytokine levels (IL-1 $\beta$, IL-6, and TNFa) [15]. Therefore, the anti-inflammatory effect of RJ-III might be the motive for its anti-nociceptive, subsequent experiments would be performed in antinociceptive mechanisms of RJ-III@HACC-SLNs.

No matter a strong bioactive RJ-III or oral SLNs with widely used due to unique physicochemical characteristics, their safety has always been a concern. Therefore, the safety evaluation of RJ-III@HACCSLNs is one of the most important parts of quality evaluation studies. In vitro cytotoxicity as well as in vivo acute toxicity studies were conducted. Cytotoxicity tests were conducted by MTT analysis in Caco-2 cells, a widely used intestinal cell barrier model [55]. Results showed SLNs and HACC@SLNs were biocompatible as previously reported [31], and safety RJ-II!HACC-SLNs has a large range of safe concentrations and its cellular activity remains unaffected when the RJ-III concentration reaches 20 $\mu \mathrm{g} / \mathrm{mL}$ in $24 \mathrm{~h}$, provided the experimental basis for cellular uptake and cellular transport study. The $\mathrm{LD}_{50}$ is often used to gauge of the toxicity of drugs and chemicals. Here, we found that the $L_{50}$ value of RJ- 
III@HACC-SLNs was 1.8 times as higher than that of RJ-III, suggesting that HACC-modified SLNs reduced the acute toxicity of RJ-III and exerted antinociceptive effects.

\section{Conclusion}

In this study, RJ-III@HACC-SLNs was prepared and its multimodal antinociceptive in vivo was investigated. We prepared RJ-III@HACC-SLNs that offered particle size in a nanometer range, good stability, as well as a prolonged-release profile. The in vivo experiments demonstrated that the RJIII@HACC-SLNs had reduced fluctuation plasma concentration, prolonged active time, and enhanced antinociceptive effects characteristics. Meanwhile, RJ-III@HACC-SLNs showed well biocompatible in Caco-2 cells and better safety whose LD $_{50}$ value is 1.8 times that of RJ-III. These results form the basis for research and development of RJ-III in analgesia application. We will investigate the long-term analgesic effects of RJ-III@HACC-SLNs in chronic pain models as well as elucidate the antinociceptive mechanisms that RJ-III@HACC-SLNs is involved.

\section{Materials And Methods 5.1 Materials}

Standard rhodojaponin III (>98\% purity) was acquired from the National Institute for the Control of Pharmaceutical and Biological Products (Beijing, China); Rhodojaponin III was obtained from the Catch Bio-Science \& Technology Co., Ltd. (Jiangsu, China) with purity more than $92 \%$. PC-98T egg yolk lecithin (AL15018, Purity $=98 \%$ ) was procured from A.V.T. Pharmaceutical Co., Ltd (Shanghai, China). GM, GT, SA, and Tween $\AA 80$ were bought from Sinopharm Chemical Reagent Co., Ltd (Shanghai, China). ATO 5 and 888 ATO were gifts from GATTEFOSSé (Saint-Priest, France). HACC (Lushen bioengineering Co, Ltd. (Nantong, China)), Dulbecco's Modified Eagle's Medium (DMEM), Penicillin/Streptomycin, Fetal Bovine Serum (FBS), Hank's Balanced Salt Solution (HBSS), and 3-(4,5-Dimethylthiazolyl-2)-2,5Diphenyltetrazolium Bromide (MTT) were the products of Thermo Fisher (Massachusetts, USA).

\subsection{Cell culture}

Caco-2 Cell lines were purchased from American Type Culture Collection (Virginia, USA) and cultured in $10 \%$ (v / v) FBS-supplemented DMEM with 1\% penicillin-streptomycin as well as 1\% (v / v) non-essential amino-acids in a $5 \% \mathrm{CO}_{2}, 90 \%$ relative humidity atmosphere at $37^{\circ} \mathrm{C}$. Medium change was done every other day while cell passaging was done every $4 \sim 6$ days through dissociation utilizing trypsin (0.25\%) EDTA (0.02\%) solution.

\subsection{Animals}

The ICR female and male mice (Grade II, 18 $22 \mathrm{~g}$ ) were from Zhejiang Wei-Tong-Li-Hua laboratory animal technology Co. LTD (Zhejiang, China), which has a production license number of SCXK (Zhejiang) 2019-0001. Mice were kept in air-conditioned rooms at $22 \sim 24{ }^{\circ} \mathrm{C}, 12 \mathrm{~h}$ light/dark cycle and provided 
with food and water ad libitum. Prior to experiments, mice were fasted overnight. The Institutional Animal Care and Use Committee of Shanghai University of Traditional Chinese Medicine approved this study (Ethical Accreditation No. PZSHUTCM200612005).

\subsection{Preparation of RJ-III@HACC-SLNs}

Rhodojaponin III-loaded solid lipid nanoparticles (RJ-III@SLNs) were prepared via an emulsificationdiffusion approach with minor modification [34]. Before the optimization, the main preparation process is as follows: $20 \mathrm{mg}$ egg yolk lecithin and $3 \mathrm{mg} \mathrm{RJ-III} \mathrm{were} \mathrm{completely} \mathrm{dissolved} \mathrm{in} \mathrm{absolute} \mathrm{alcohol} \mathrm{and}$ thereafter mixed with glycerol monostearate $(30 \mathrm{mg})$ to form an oil phase. Vacuum rotary evaporation was used to remove the organic solvent to obtain a lipid film layer. Under sustained ultrasound, $10 \mathrm{~mL}$ water phase supplemented with $0.2 \%$ (w/v) Tween-80 was added to the lipid film in 30 min using a needle. The RJ-III@SLNs were obtained after intermittent sonication by a probe sonicator (Xinzhi, Ningbo, China) at $400 \mathrm{w}$ for 4 min (2s/3s). RJ-III@HACC-SLNs was obtained by binding HACC to the surface of RJ-III@SLNs via electrostatic adsorption [31]. In brief, 4 mL RJ-III@SLNs was added to 8 mL HACC solution $(0.1 \%, w / v)$, followed by further stirring for $1 \mathrm{~h}$.

\subsection{Optimization of RJ-III@HACC-SLNs}

To develop efficient RJ-III@HACC-SLNs, a single factor experiment was conducted. The design of RJIII@HACC-SLNs in basic terms, is dependent on the HACC coating and type of lipid used. Previous works showed that the particle sizes of SLNs were markedly affected by volume ratios of $V_{H}$ to $V_{S}$ and stirring time in the modification process [31]. However, the zeta potential and EE, important factors for stability and effectiveness, were not studied in the modification process. Therefore, we optimized the process of preparing modified RJ-IIISLNs, several parameters, including volume ratio of $\mathrm{V}_{\mathrm{S}}$ to $\mathrm{V}_{\mathrm{H}}$ and stirring time on particles size, zeta potential, and EE, were investigated. The solid lipid had a marked effect on the EE and particle sizes of SLNs due to their different molecular weight and solubility [22]. So, we selected core lipids by comparing the EE, zeta potential, and particle size of RJ-III@HACC-SLNs based on five commonly and different molecular weight used solid lipids (GM, GT, SA, ATO 5, and 888 ATO). Table 3 shows formulations of the SLNs. 
Table 3

Formulations of the various solid lipid nanoparticles

\begin{tabular}{|llll|}
\hline Number & Lipid & $\mathbf{V}_{\mathbf{H}}: \mathbf{V}_{\mathbf{S}}$ & Stirring time $(\mathbf{h})$ \\
\hline 1 & Glycerol monostearate & $4: 1$ & 1 \\
\hline 2 & Glycerol monostearate & $2: 1$ & 1 \\
\hline 3 & Glycerol monostearate & $1: 1$ & 1 \\
\hline 4 & Glycerol monostearate & $2: 1$ & 1 \\
\hline 5 & Glycerol monostearate & $2: 1$ & 2 \\
\hline 6 & Glycerol monostearate & $2: 1$ & 4 \\
\hline 7 & Glycerol monostearate & $2: 1$ & 1 \\
\hline 8 & Glyceryl trioleate & $2: 1$ & 1 \\
\hline 9 & Stearic acid & $2: 1$ & 1 \\
\hline 10 & Precirol ATO 5 & $2: 1$ & 1 \\
\hline 11 & Compritol 888 ATO & $2: 1$ & 1 \\
\hline
\end{tabular}

\subsection{Characterization of RJ-III@HACC-SLNs}

The morphology of RJ-III@HACC-SLNs was performed by TEM (FEI Talos, Thermo Fisher Scientific, USA), while zeta potentials and particle sizes were measured using a Zeta Potential / Particle Sizer (Nicomp 380 ZLS, PSS.NICOMP, USA). The changes in solid-state forms of RJ-III in SLNs were evaluated by XRD (Rikagu, D / Max-3C, Japan). FT-IR spectrophotometer (IRAffinity-1S, SHIMADZU, Japan) was used to evaluate the surface chemistry structure of RJ-III, SLNs, RJ-II!@SLNs, RJ-III@HACC-SLNs, to assess the surface characterization of RJ-III@HACC-SLNs. The EE of RJ-III@HACC-SLNs were assessed by high performance liquid chromatography (HPLC) and ultrafiltration centrifugation. Briefly, the unencapsulated RJ-III was isolated from RJ-III@HACC-SLNs through 20 KD ultrafiltration centrifuge tube (Millipore, USA) at $10000 \mathrm{rpm}$ for $30 \mathrm{~min}$. Total drug amounts in drug-loaded SLNs were evaluated by dissolving SLNs in methanol to release encapsulated RJ-III, and assayed by HPLC. The conditions for the HPLC system (Agilent-1260B, Agilent, USA) equipped with an evaporative light scattering detector (Agilent-G460B, Agilent, USA) were: CAPCELL PAK $\mathrm{C}_{18}$ column $(4.6 \times 150 \mathrm{~mm}, 5 \mu \mathrm{m})$; mobile phase, acetonitrile-water $(30: 70, \mathrm{v} / \mathrm{v}, 1.0 \mathrm{~mL} / \mathrm{min})$; injection temperature, $25^{\circ} \mathrm{C}$; evaporation temperature, $60^{\circ} \mathrm{C}$; atomization temperature, $30^{\circ} \mathrm{C}$; sample volume, $20 \mu \mathrm{L}$. The equation for calculating EE was: 
$\mathrm{EE} \%=\mathrm{m}_{2} / \mathrm{m}_{1} \times 100 \%$

$\mathrm{m}_{1}=$ Total drug

$\mathrm{m}_{2}=$ Total drug-free drug

\subsection{In vitro stability and release of RJ-III@ HACC-SLNs}

The stability in vitro of RJ-III@SLNs and RJ-III@HACC-SLNs were studied by previous reports [31]. Incubation of nanoparticles was done at $37^{\circ} \mathrm{C}$ in SGF. Samples were obtained at $0,1,2$, and $3 \mathrm{~h}$, and assessed for changes in EE. SGF was constituted using $2 \mathrm{~g}$ sodium chloride, $36.5 \% 7 \mathrm{~mL}$ hydrochloric acid, and pepsin (3.2 g) in $1000 \mathrm{~mL}$ of water.

The In vitro release investigation of RJ-III@HACC-SLNs, RJ-III@SLNs, and RJ-III were performed in PBS of $\mathrm{pH} 6.8$ by the dialysis bag (molecular weight cut off 8 14kDa) diffusion technique. The test samples were stored inside the bag (equivalent to $3 \mathrm{mg} \mathrm{RJ}$-III), dipped into $200 \mathrm{~mL}$ medium at $(37 \pm 0.5){ }^{\circ} \mathrm{C}$ in a conical flask with a stirring speed of 100 rpm. $2 \mathrm{~mL}$ samples were taken and instantly replaced with an equal volume of fresh release medium at pre-set time $0.25,0.5,1,2,4,8,12,24 \mathrm{~h}$. Amounts of RJ-III in the medium were also determined using the HPLC method mentioned above in 5.6.

\subsection{Pharmacokinetic studies}

The RJ-III@HACC-SLNs oral absorption was evaluated by pharmacokinetic parameters, the pharmacokinetic study was performed in mice. The mice were randomized into several groups (6 mice per group) and intragastrically administered with RJ-III or RJ-III@HACC-SLNs containing RJ-III $0.2 \mathrm{mg} / \mathrm{kg}$ [19]. With regards to pharmacokinetic assays, mice have anesthetized using diethyl ether at $0.033,0.083$, $0.25,0.5,1,2,3,4,6$, and $8 \mathrm{~h}$ time points, after administration, venous blood samples were obtained from saphenous veins of the thighs into tubes containing EDTA- $K_{2}$. Plasma samples were obtained by centrifugation $\left(6,000 \mathrm{rpm}, 8 \mathrm{~min}, 4^{\circ} \mathrm{C}\right)$, and were then quantified according to the LC-MS/MS method previously studied by the research group [19]. Chromatographic separation was performed using an ACQUITY UPLC HSS T3 $(1.8 \mu \mathrm{m}, 2.1 \times 50 \mathrm{~mm})$ reverse-phase column (Waters technology (Shanghai) Co., LTD (Shanghai, China)). The column was equipped with an AF0-8497 guard column (Phenomenex, CA, USA) and maintained at room temperature. The flow rate and sample injection volume were $0.5 \mathrm{~mL} / \mathrm{min}$ and $10 \mu \mathrm{L}$, respectively [19]. Non-compartmental analysis was conducted using the WinNonlin®8.2.0 software (Pharsight, CA, USA) to obtain pharmacokinetic parameters.

\subsection{Multimodal analgesia studies of RJ-III@HACC-SLNs}

The multimodal analgesic effects of RJ-III@HACC-SLNs were determined using the acetic acid writhing and hot plate, and formalin tests. The acetic acid writhing test was separated into two parts. In the first 
part, 40 mice were assigned into 4 groups $(\mathrm{n}=10)$ and pretreated with RJ-III@HACC-SLNs $(0.10 \mathrm{mg} / \mathrm{kg}$ of RJ-III, i.g), RJ-III (0.10 mg/kg, i.g), aspirin (200 mg/kg, i.g) or normal saline (0.9\% NaCl, i.g). After $15 \mathrm{~min}$, mice were administered with $0.8 \%$ acetic acid $(10 \mathrm{~mL} / \mathrm{kg}$, ip) and the nociception intensity evaluated by counting the number of abdominal contortions, such as abdominal muscle contractions and extensions of hind paws for $30 \mathrm{~min}$. In the second part of the experiment as before, but the time of acetic acid intervention was $45 \mathrm{~min}$ after administration. The pharmacodynamics of every preparation was evaluated by comparing the number of writhing.

In the hot plate test, firstly, each mouse was placed thrice on the heated plate $(53 \pm 0.5){ }^{\circ} \mathrm{C}$ at a $15 \mathrm{~min}$ interval to obtain a basal pain threshold which is the reaction time about paw lick time or jump. Mice with reaction < $5 \mathrm{~s}$ or $>30$ s longer were omitted. Then, the animals $(n=10)$ received RJ-III@HACC-SLNs (contain $0.20 \mathrm{mg} / \mathrm{kg} \mathrm{RJ-III,} \mathrm{i.g),} \mathrm{RJ-III} \mathrm{(} 0.20 \mathrm{mg} / \mathrm{mg}$, i.g), aspirin $(200 \mathrm{mg} / \mathrm{kg}$, i.g) or normal saline $(0.9 \%$ $\mathrm{NaCl}$, i.g). Reaction times were evaluated at 15 and $45 \mathrm{~min}$ after administration, with $30 \mathrm{~s}$ as the cutoff time to avoid injury to the paw.

The formalin test was divided into two parts as similar to acetic acid writhing test. In the first part, the mice $(\mathrm{n}=10)$ were treated with RJ-III@HACC-SLNs (contain $0.10 \mathrm{mg} / \mathrm{kg} \mathrm{RJ-III,} \mathrm{i.g),} \mathrm{RJ-III} \mathrm{(0.10} \mathrm{mg/kg,} \mathrm{i.g),}$ aspirin $(200 \mathrm{mg} / \mathrm{kg}$, i.g) or normal saline $(0.9 \% \mathrm{NaCl}$, i.g) 15 min before $25 \mu \mathrm{L}$ of $2.5 \%$ formalin subcutaneous injection. The licking as well as biting time about the injected left hind paw, indicating pain, was documented from 0 to $5 \mathrm{~min}$ (phase I, neurogenic phase) and from 15 to $30 \mathrm{~min}$ (phase II, inflammatory phases). Findings were presented as licking time, in seconds (s). In the second part of the experiment as before, but the time of formalin intervention was $45 \mathrm{~min}$ after administration. Finally, the antinociceptive effect of each preparation was determined by comparing the time of licking and biting.

\subsection{In vitro cytotoxicity}

The biocompatibility of RJ-III@HACC-SLNs was assessed by cytotoxicity of Caco-2 cells [55]. In the cytotoxicity study, the Caco- 2 cells were cultured at $1.5 \times 10^{5}$ cells/well in 96-well plates, and incubated for form cell layers. Test solutions were assigned into five groups of Blank SLNs (SLNs), Blank SLNs modified by HACC (HACC-SLNs), RJ-III, RJ-III@SLNs, and RJ-III@HACC-SLNs. The cell layers were obtained and rinsed 3 times using HBSS. Then, cells were incubated with $200 \mu \mathrm{L}$ of various concentrations of blank nanocarriers $(1,2,5,10,50,100$, and $500 \mu \mathrm{g} / \mathrm{mL})$, and nanoformulations with RJIII at different doses (total amount of RJ-III in SLNs of $0.1,0.2,0.5,1,2,5$, and $10 \mu \mathrm{g} / \mathrm{mL}$ ) for $24 \mathrm{~h}$. Cell layers treated with blank culture medium $(200 \mu \mathrm{L})$ were the controls of $100 \%$ viability. After incubation, the addition of MTT solution $(20 \mu \mathrm{L} ; 5 \mathrm{mg} / \mathrm{mL})$ was followed by further incubation for $4 \mathrm{~h}$. Subsequently, the MTT dye was removed from wells and $200 \mu \mathrm{L}$ of dimethyl sulfoxide was added to each well to solubilize the formazan crystals. The results were quantified using a microplate reader at $570 \mathrm{~nm}$.

\section{Cell viability $\%=\mathrm{OD}_{2} / \mathrm{OD}_{1} \times 100 \%$}

$\mathrm{OD}_{1}$ is the absorbance intensity of the untreated cells, while $\mathrm{OD}_{2}$ is the absorbance intensity of the treated cells. 


\subsection{In vivo acute toxicity test}

To evaluate the safety of RJ-III-HACC@SLNs in vivo, acute lethal characteristics were assayed as previously reported, with minor changes [14]. Briefly, after 3 days of adaptation, 80 mice were randomized into 10 groups $(n=8)$. Ever group was administered RJ-III $(1.711,2.312,3.125,4.223,5.707 \mathrm{mg} / \mathrm{kg}$, obtained from our previous studies) or RJ-III@HACC-SLNs (total amount of RJ-III in SLNs of 3.423, 4.625, $6.250,8.446,11.413 \mathrm{mg} / \mathrm{kg}$, based on a preliminary experiment) by single intragastric administration, and cumulative mortality within 7 days was recorded to calculate median lethal dose $\left(\operatorname{LD}_{50}\right)$ by Bliss method [56].

\subsection{Statistical analyses}

Results are shown as mean \pm standard error $(n=3)$. The one-way or two-way ANOVA were performed using Origin 2021b software. $P<0.05, P<0.01$ and $P<0.001$ were significance thresholds.

\section{Declarations}

\section{Acknowledgments}

This work was financially supported by the science and technology support project of the Shanghai Science and technology commission (14401901400).

Conflicts of interest

The authors state no conflict of interest.

Authors' contributions

\# QYY and JY contributed equally to this work. Designed the experiments: QYY, JY, MCL and JQZ. Executed the experiments: QYY, JY, SGS, and JYZ; Analyzed the data: QYY, JY, YF and JQZ; Wrote the paper: QYY, JY, and MCL. All authors read and approved the final manuscript.

\section{Funding}

This funding was supported by the science and technology support project of the Shanghai Science and technology commission (14401901400).

Availability of data and materials

All data generated or analysed during this study are included in this published article.

Ethics approval and consent to participate 
Experimental protocols involving the use of animals were reviewed and approved by the institutional animal care and use committee of Shanghai University of Traditional Chinese Medicine. (Ethical Accreditation No. PZSHUTCM200612005).

Consent for publication

Not applicable.

Competing interests

The authors declare that they have no competing interests.

Author details

Engineering Research Center of Modern Preparation Technology of TCM of Ministry of Education, Shanghai University of Traditional Chinese Medicine, 1200 Cailun Road, Shanghai 201203, PR China

\section{References}

1. Loeser JD, Melzack R. Pain: an overview. Lancet. 1999;353:1607-9. https://doi.org/10.1016/S01406736(99)01311-2.

2. Mogil JS. Qualitative sex differences in pain processing: emerging evidence of a biased literature. Nat Rev Neurosci. 2020;21:353-65. https://doi.org/10.1038/s41583-020-0310-6.

3. Melnikova I. Pain market. Nat Rev Drug Discovery. 2010;9::589-90. https://doi.org/10.1038/nrd3226.

4. Shaheed CA, Machado GC, Underwood M. Drugs for chronic pain. Br J Gen Pract. 2020;70:576-7. https://doi.org/10.3399/bjgp20X713549.

5. Kuehn B. Chronic Pain Prevalence. Jama. 2018;320:1632. https://doi.org/10.1001/jama.2018.16009.

6. Arenas OM, Lumpkin EA. Touching Base with Mechanical Pain. Cell. 2020;180:824-6. https://doi.org/10.1016/j.cell.2020.02.022.

7. Goldberg DS, McGee SJ. Pain as a global public health priority. BMC Public Health. 2011;11:770. https://doi.org/10.1186/1471-2458-11-770.

8. Jackson T, Thomas S, Stabile V, Shotwell M, Han X, McQueen K. A Systematic Review and MetaAnalysis of the Global Burden of Chronic Pain Without Clear Etiology in Low- and Middle-Income Countries: Trends in Heterogeneous Data and a Proposal for New Assessment Methods. Anesth Analg. 2016;123::739-48. https://doi.org/10.1213/ANE.0000000000001389.

9. Woodcock J. A difficult balance-pain management, drug safety, and the FDA. N Engl J Med. 2009;361::2105-7. https://doi.org/10.1056/NEJMp0908913.

10. Cai Y-Q, Hu J-H, Qin J, Sun T, Li X-L. Rhododendron Molle (Ericaceae): phytochemistry, pharmacology, and toxicology. Chin J Nat Med. 2018;16:401-10. https://doi.org/10.1016/s1875-5364(18)30073-6. 
11. Cai YQ, Hu JH, Qin J, Sun T, Li XL. Rhododendron Molle (Ericaceae): phytochemistry, pharmacology, and toxicology. Chin J Nat Med. 2018;16:401-10. https://doi.org/10.1016/S1875-5364(18)30073-6.

12. Zhi X, Xiao L, Liang S, Yi F, Ruan KF. Chemical constituents of Rhododendron molle. Chem Nat Compd. 2013;49:454-6. https://doi.org/10.1007/s10600-013-0637-6.

13. Zou HY, Luo J, Xu DR, Kong LY. Tandem Solid-Phase Extraction Followed by HPLC-ESI/QTOF/MS/MS for Rapid Screening and Structural Identification of Trace Diterpenoids in Flowers of Rhododendron molle. Phytochem Anal. 2014,25:255-65. https://doi.org/10.1002/pca.2501.

14. Li Y, Liu YB, Zhang JJ, Liu Y, Ma SG, Qu J, Lv HN, Yu SS. Antinociceptive Grayanoids from the Roots of Rhododendron molle. J Nat Prod. 2015;78:2887-95.

https://doi.org/10.1021/acs.jnatprod.5b00456.

15. He YC, Yao YM, Xue QW, Fang X, Liang S. Anti-rheumatoid arthritis potential of diterpenoid fraction derived from Rhododendron molle fruits. Chin J Nat Med. 2021;19::181-7. https://doi.org/10.1016/s1875-5364(21)60019-5.

16. Mao HY, Li CY, Cui JJ, Feng YB, Hu WS, Guo QG, Jiang MX. Rhomotoxin pharmacologic action in lowering blood pressure and slowing heart rate. Chin Med J (Engl). 1982;95:311-8.

17. Zhou JF, Liu TT, Zhang HQ, Zheng GJ, Qiu Y, Deng MY, Zhang C, Yao GM. Anti-inflammatory Grayanane Diterpenoids from the Leaves of Rhododendron molle. J Nat Prod. 2018;81:151-61. https://doi.org/10.1021/acs.jnatprod.7b00799.

18. Huizhen C, Boping D, Nianbao Z, Lei C, Zhengui H. Extraction of Rhomotoxin and Its LD50. China Pharmaceuticals. 2010;19:10-1.

19. Zhang JQ, Zhao CC, Yang QY, Liang S, Wu F, Ma BL, Feng Y. Pharmacokinetics, bioavailability and tissue distribution studies of rhodojaponin III in mice using QTRAP LC-MS/MS. Biomedical Chromatography. 2019. https://doi.org/10.1002/bmc.4649.

20. Nunes S, Madureira AR, Campos D, Sarmento B, Gomes AM, Pintado M, Reis F. Solid lipid nanoparticles as oral delivery systems of phenolic compounds: Overcoming pharmacokinetic limitations for nutraceutical applications. Crit Rev Food Sci Nutr. 2017;57:1863-73. https://doi.org/10.1080/10408398.2015.1031337.

21. Mirchandani Y, Patravale VB. S B. Solid lipid nanoparticles for hydrophilic drugs. J Control Release. 2021;335:457-64. https://doi.org/10.1016/j.jconrel.2021.05.032.

22. Mehnert W, Mäder K. Solid lipid nanoparticles: production, characterization and applications. Adv Drug Deliv Rev. 2001;47:165-96. https://doi.org/10.1016/s0169-409x(01)00105-3.

23. Wong CY, Al-Salami H, Dass CR. Potential of insulin nanoparticle formulations for oral delivery and diabetes treatment. J Control Release. 2017;264:247-75. https://doi.org/10.1016/j.jconrel.2017.09.003.

24. Du Y, Ling L, Ismail M, He W, Xia Q, Zhou W, Yao C, Li X. Redox sensitive lipid-camptothecin conjugate encapsulated solid lipid nanoparticles for oral delivery. Int J Pharm. 2018;549:352-62. https://doi.org/10.1016/j.ijpharm.2018.08.010. 
25. Ganesan P, Ramalingam P, Karthivashan G, Ko YT, Choi DK. Recent developments in solid lipid nanoparticle and surface-modified solid lipid nanoparticle delivery systems for oral delivery of phytobioactive compounds in various chronic diseases. Int J Nanomedicine. 2018;13:1569-83. https://doi.org/10.2147/IJN.S155593.

26. Salah E, Abouelfetouh MM, Pan Y, Chen D, Xie S. Solid lipid nanoparticles for enhanced oral absorption: A review. Colloids Surf B Biointerfaces. 2020;196:111305. https://doi.org/10.1016/j.colsurfb.2020.111305.

27. Cho J, Grant J, Piquette-Miller M, Allen C. Synthesis and physicochemical and dynamic mechanical properties of a water-soluble chitosan derivative as a biomaterial. Biomacromol. 2006;7:2845-55. https://doi.org/10.1021/bm060436s.

28. Xu X, Li Y, Wang F, Lv L, Liu J, Li M, Guo A, Jiang J, Shen Y, Guo S. Synthesis, in vitro and in vivo evaluation of new norcantharidin-conjugated hydroxypropyltrimethyl ammonium chloride chitosan derivatives as polymer therapeutics. Int J Pharm. 2013;453:610-9. https://doi.org/10.1016/j.ijpharm.2013.05.052.

29. Shi C, Zhu P, Chen N, Ye X, Wang Y, Xiao S. Preparation and sustainable release of modified konjac glucomannan/chitosan nanospheres. Int J Biol Macromol. 2016;91::609-14. https://doi.org/10.1016/j.jibiomac.2016.05.073.

30. Xiao B, Ma P, Ma L, Chen Q, Si X, Walter L, Merlin D. Effects of tripolyphosphate on cellular uptake and RNA interference efficiency of chitosan-based nanoparticles in Raw 264.7 macrophages. $J$ Colloid Interface Sci. 2017;490:520-8. https://doi.org/10.1016/j.jcis.2016.11.088.

31. Shi LL, Xie H, Lu J, Cao Y, Liu JY, Zhang XX, Zhang H, Cui JH, Cao QR. Positively Charged SurfaceModified Solid Lipid Nanoparticles Promote the Intestinal Transport of Docetaxel through Multifunctional Mechanisms in Rats. Mol Pharm. 2016;13:2667-76. https://doi.org/10.1021/acs.molpharmaceut.6b00226.

32. Custodio JM, Wu CY, Benet LZ. Predicting drug disposition, absorption/elimination/transporter interplay and the role of food on drug absorption. Adv Drug Deliv Rev. 2008;60::717-33. https://doi.org/10.1016/j.addr.2007.08.043.

33. Hwang SR, Byun Y. Advances in oral macromolecular drug delivery. Expert Opin Drug Deliv. 2014; 11:1955-1967. https://doi.org/10.1517/17425247.2014.945420.

34. Zhang L, Zhu K, Zeng H, Zhang J, Pu Y, Wang Z, Zhang T, Wang B. Resveratrol solid lipid nanoparticles to trigger credible inhibition of doxorubicin cardiotoxicity. Int $\mathrm{J}$ Nanomedicine. 2019;14::6061-71. https://doi.org/10.2147/IJN.S211130.

35. Keck CM, Müller RH. Nanotoxicological classification system (NCS) - a guide for the risk-benefit assessment of nanoparticulate drug delivery systems. Eur J Pharm Biopharm. 2013;84::445-8. https://doi.org/10.1016/j.ejpb.2013.01.001.

36. Omwoyo WN, Melariri P, Gathirwa JW, Oloo F, Mahanga GM, Kalombo L, Ogutu B, Swai H. Development, characterization and antimalarial efficacy of dihydroartemisinin loaded solid lipid nanoparticles. Nanomedicine. 2016;12::801-9. https://doi.org/10.1016/j.nano.2015.11.017. 
37. Chien TY, Huang SK, Lee CJ, Tsai PW, Wang CC. Antinociceptive and Anti-Inflammatory Effects of Zerumbone against Mono-lodoacetate-Induced Arthritis. Int J Mol Sci. 2016;17:249. https://doi.org/10.3390/ijms17020249.

38. Hernandez-Leon A, Gonzalez-Trujano ME, Narvaez-Gonzalez F, Perez-Ortega G, Rivero-Cruz F, Aguilar MI. Role of beta-Caryophyllene in the Antinociceptive and Anti-Inflammatory Effects of Tagetes lucida Cav. Essential Oil Molecules. 2020; 25. https://doi.org/10.3390/molecules25030675.

39. Gomes Junior AL, Islam MT, Nicolau LAD, de Souza LKM, Araujo TSL, Lopes de Oliveira GA, de Melo Nogueira K, da Silva Lopes L, Medeiros JR, Mubarak MS, Melo-Cavalcante AAC. Anti-Inflammatory. Antinociceptive, and Antioxidant Properties of Anacardic Acid in Experimental Models. ACS Omega. 2020;5:19506-15. https://doi.org/10.1021/acsomega.0c01775.

40. Costa LEC, Brito TV, Damasceno ROS, Sousa WM, Barros FCN, Sombra VG, Junior JSC, Magalhaes DA, Souza M, Medeiros JR, et al. Chemical structure, anti-inflammatory and antinociceptive activities of a sulfated polysaccharide from Gracilaria intermedia algae. Int J Biol Macromol. 2020;159:96675. https://doi.org/10.1016/j.ijbiomac.2020.05.166.

41. Montiel-Ruiz RM, Cordova-de la Cruz M, Gonzalez-Cortazar M, Zamilpa A, Gomez-Rivera A, LopezRodriguez R, Lobato-Garcia CE, Ble-Gonzalez EA. Antinociceptive Effect of Hinokinin and Kaurenoic Acid Isolated from Aristolochia odoratissima L. Molecules. 2020; 25. https://doi.org/10.3390/molecules25061454.

42. Wang $D$, Yang $H$, Liang $Y$, Wang $X$, Du X, Li R, Jiang Y, Ye J. Antinociceptive Effect of Spirocyclopiperazinium Salt Compound DXL-A-24 and the Underlying Mechanism. Neurochem Res. 2019;44:2786-95. https://doi.org/10.1007/s11064-019-02899-x.

43. Dahlhamer J, Lucas J, Zelaya C, Nahin R, Mackey S, DeBar L, Kerns R, Von Korff M, Porter L, Helmick C. Prevalence of Chronic Pain and High-Impact Chronic Pain Among Adults - United States, 2016. MMWR Morb Mortal Wkly Rep. 2018;67:1001-6. https://doi.org/10.15585/mmwr.mm6736a2.

44. Wang R, Han L, Gao Q, Chen D, Wang Y, Zhang X, Yu X, Zhang Y, Li Z, Bai C. Progress on Active Analgesic Components and Mechanisms of Commonly Used Traditional Chinese Medicines: A Comprehensive Review. J Pharm Pharm Sci. 2018;21:437-80. https://doi.org/10.18433/jpps30212.

45. Wang FC, Marangoni AG. Internal and external factors affecting the stability of glycerol monostearate structured emulsions. RSC Advances. 2015;5:93108-16. https://doi.org/10.1039/c5ra18748f.

46. Talele P, Sahu S, Mishra AK. Physicochemical characterization of solid lipid nanoparticles comprised of glycerol monostearate and bile salts. Colloids Surf B Biointerfaces. 2018;172:517-25. https://doi.org/10.1016/j.colsurfb.2018.08.067.

47. Hu X, Yang G, Chen S, Luo S, Zhang J. Biomimetic and bioinspired strategies for oral drug delivery. Biomater Sci. 2020;8::1020-44. https://doi.org/10.1039/c9bm01378d.

48. Liu L, Yao W, Rao Y, Lu X, Gao J. pH-Responsive carriers for oral drug delivery: challenges and opportunities of current platforms. Drug Deliv. 2017;24:569-81. https://doi.org/10.1080/10717544.2017.1279238. 
49. Banerjee A, Qi J, Gogoi R, Wong J, Mitragotri S. Role of nanoparticle size, shape and surface chemistry in oral drug delivery. J Control Release. 2016;238::176-85. https://doi.org/10.1016/j.jconrel.2016.07.051.

50. Iqbal A, Zaman M, Wahab Amjad M, Adnan S, Abdul Ghafoor Raja M, Haider Rizvi SF, Mustafa MW, Farooq U, Abbas G, Shah S. Solid Lipid Nanoparticles of Mycophenolate Mofetil: An Attempt to Control the Release of an Immunosuppressant. Int J Nanomedicine. 2020;15:5603-12. https://doi.org/10.2147/IJN.S255636.

51. Peck J, Urits I, Zeien J, Hoebee S, Mousa M, Alattar H, Kaye AD, Viswanath O. A Comprehensive Review of Over-the-counter Treatment for Chronic Migraine Headaches. Curr Pain Headache Rep. 2020;24::19. https://doi.org/10.1007/s11916-020-00852-0.

52. Sabat R, Jemec GBE, Matusiak L, Kimball AB, Prens E, Wolk K. Hidradenitis suppurativa. Nat Rev Dis Primers. 2020;6:18. https://doi.org/10.1038/s41572-020-0149-1.

53. Chen G, Zhang YQ, Qadri YJ, Serhan CN, Ji RR. Microglia in Pain: Detrimental and Protective Roles in Pathogenesis and Resolution of Pain. Neuron. 2018;100:1292-311.

https://doi.org/10.1016/j.neuron.2018.11.009.

54. Risbud MV, Shapiro IM. Role of cytokines in intervertebral disc degeneration: pain and disc content. Nat Rev Rheumatol. 2014;10:44-56. https://doi.org/10.1038/nrrheum.2013.160.

55. Yu Z, Fan W, Wang L, Qi J, Lu Y, Wu W. Effect of Surface Charges on Oral Absorption of Intact Solid Lipid Nanoparticles. Mol Pharm. 2019;16:5013-24. https://doi.org/10.1021/acs.molpharmaceut.9b00861.

56. Bai K, Hong B, He J, Hong Z, Tan R. Preparation and antioxidant properties of selenium nanoparticles-loaded chitosan microspheres. Int J Nanomedicine. 2017;12:4527-39. https://doi.org/10.2147/IJN.S129958.

\section{Figures}

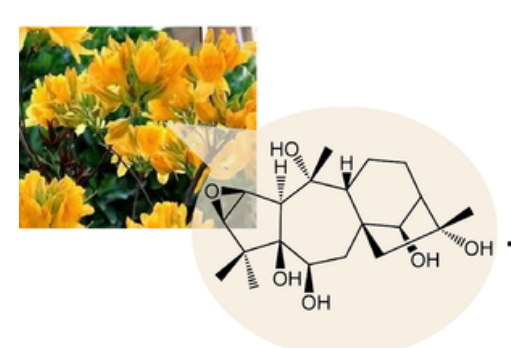

Rhodojaponin III (RJ-III)

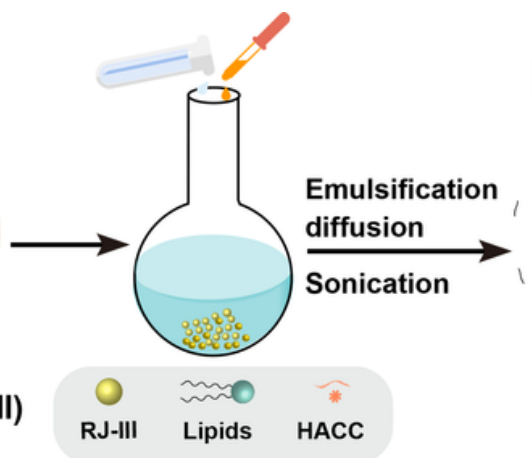

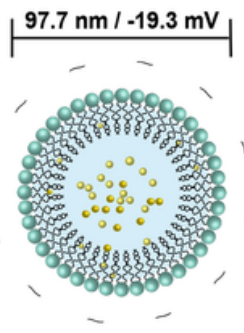

RJ-III-SLNs



RJ-III@HACC-SLNs

\section{Figure 1}

The preparation procedure of RJ-III@HACC-SLNs. 
A
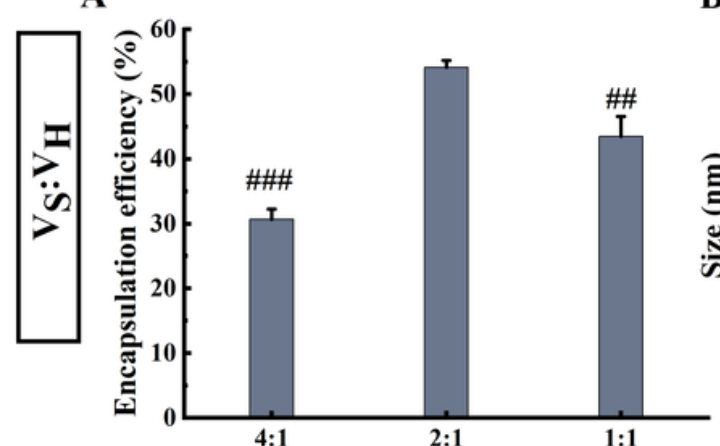

B

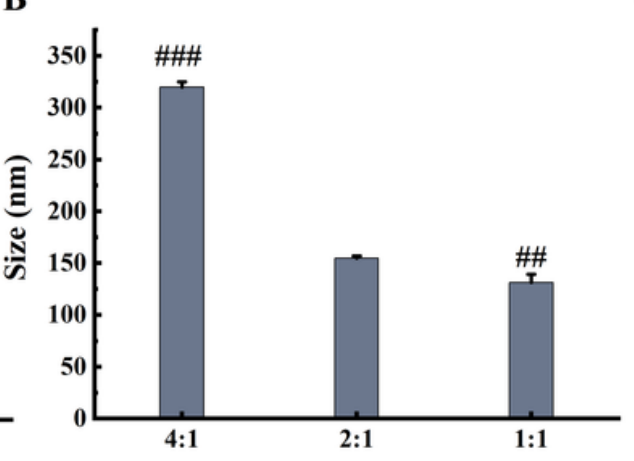

E



C

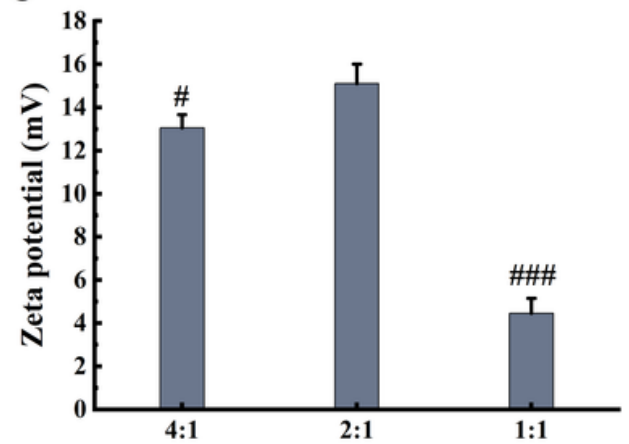

F

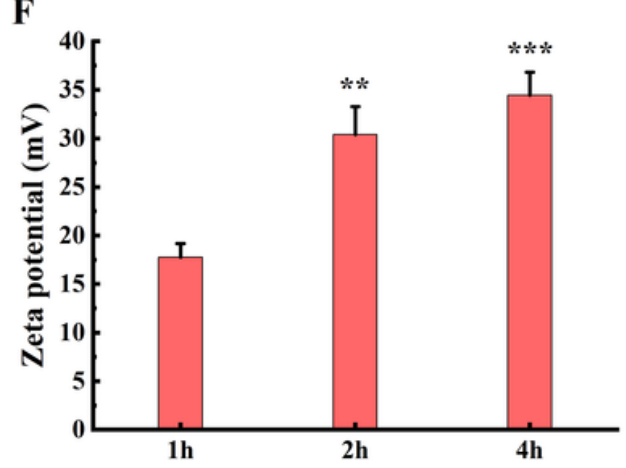

Figure 2

The optimized modification process of RJ-III@HACC-SLNs (Mean $\pm S D, n=3$ ). Influences of various volume ratios of HACC liquid $\left(V_{H}\right)$ to $S L N s$ suspension $\left(V_{S}\right)$ on encapsulation efficiency $(A)$, particle size (B), and zeta potential (C) of RJ-II! @HACC-SLNs. The effects of different stirring time encapsulation efficiency (D), particle sizes (E), and zeta potentials (F) of RJ-III@HACC-SLNs. ${ }^{\#} P<0.05$ and ${ }^{\# \#} P<0.01$ and ${ }^{\# \# \#} P<0.001$ vs. the $2: 1$ group; ${ }^{\star} P<0.05$ and ${ }^{* \star} P<0.01$ and ${ }^{* \star} P<0.001$ vs. the 1 h group. 

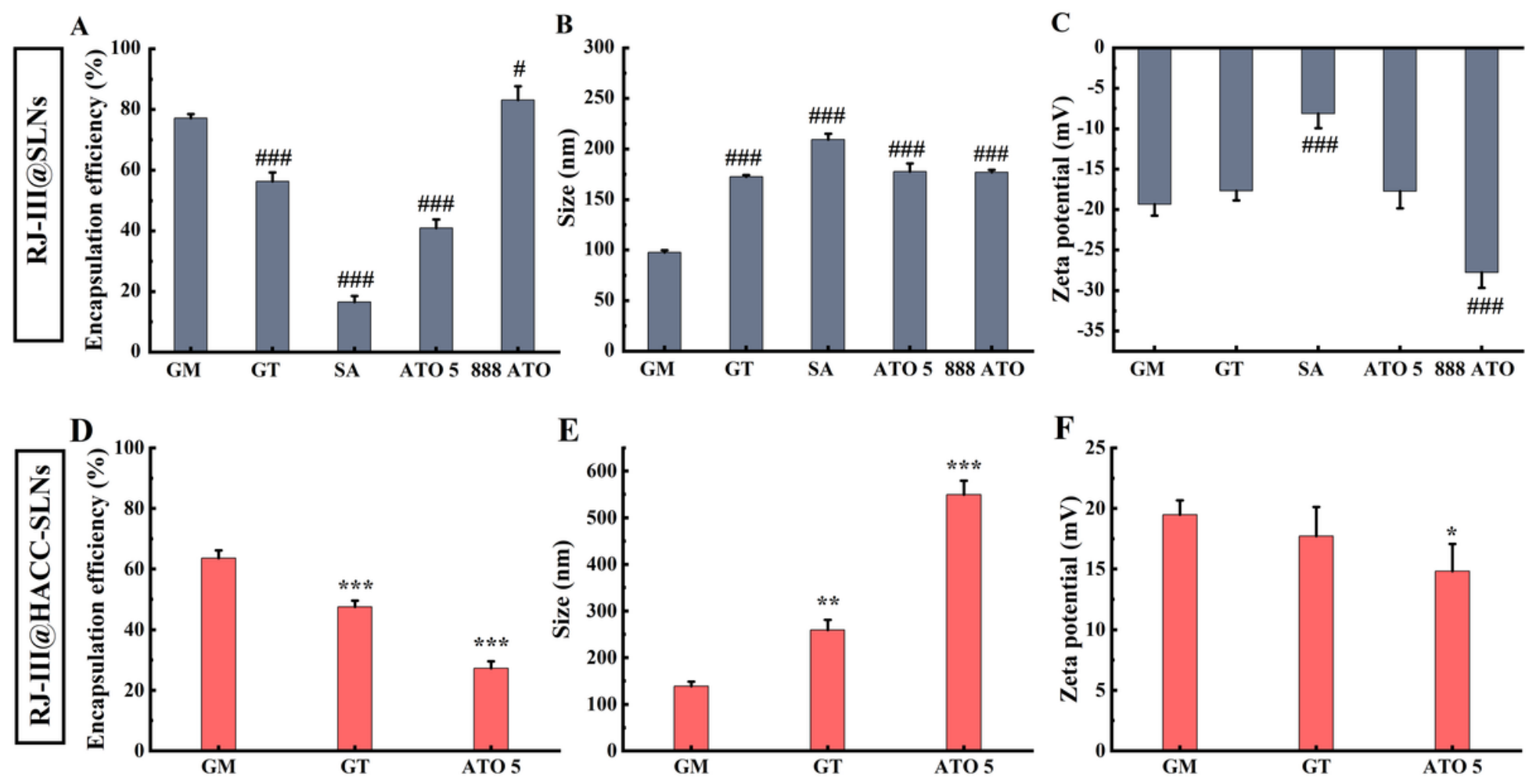

Figure 3

The screening of the core lipids of nanoparticles of RJ-III@HACC-SLNs (Mean \pm SD, $n=3$ ). The effect of different lipids on particle size (A), zeta potential (B), and encapsulation efficiency (C) of RJ-III@SLNs. $P$ $<0.05$ and ${ }^{\# \#} P<0.01$ and ${ }^{\# \# \#} P<0.001$ vs. GM group. The influences of different lipids on particle size (D), zeta potential (E), and encapsulation efficiency (F) of RJ-III@HACC-SLNs, ${ }^{*} P<0.05$ and ${ }^{* \star} P<0.01$ and ${ }^{* * \star} P<0.001$ vs. the GM group. Abbreviations: GM, Glycerol monostearate; GT: glyceryl trioleate; SA, stearic acid; ATO 5, Precirol ATO 5; 888 ATO, Compritol 888 ATO. 

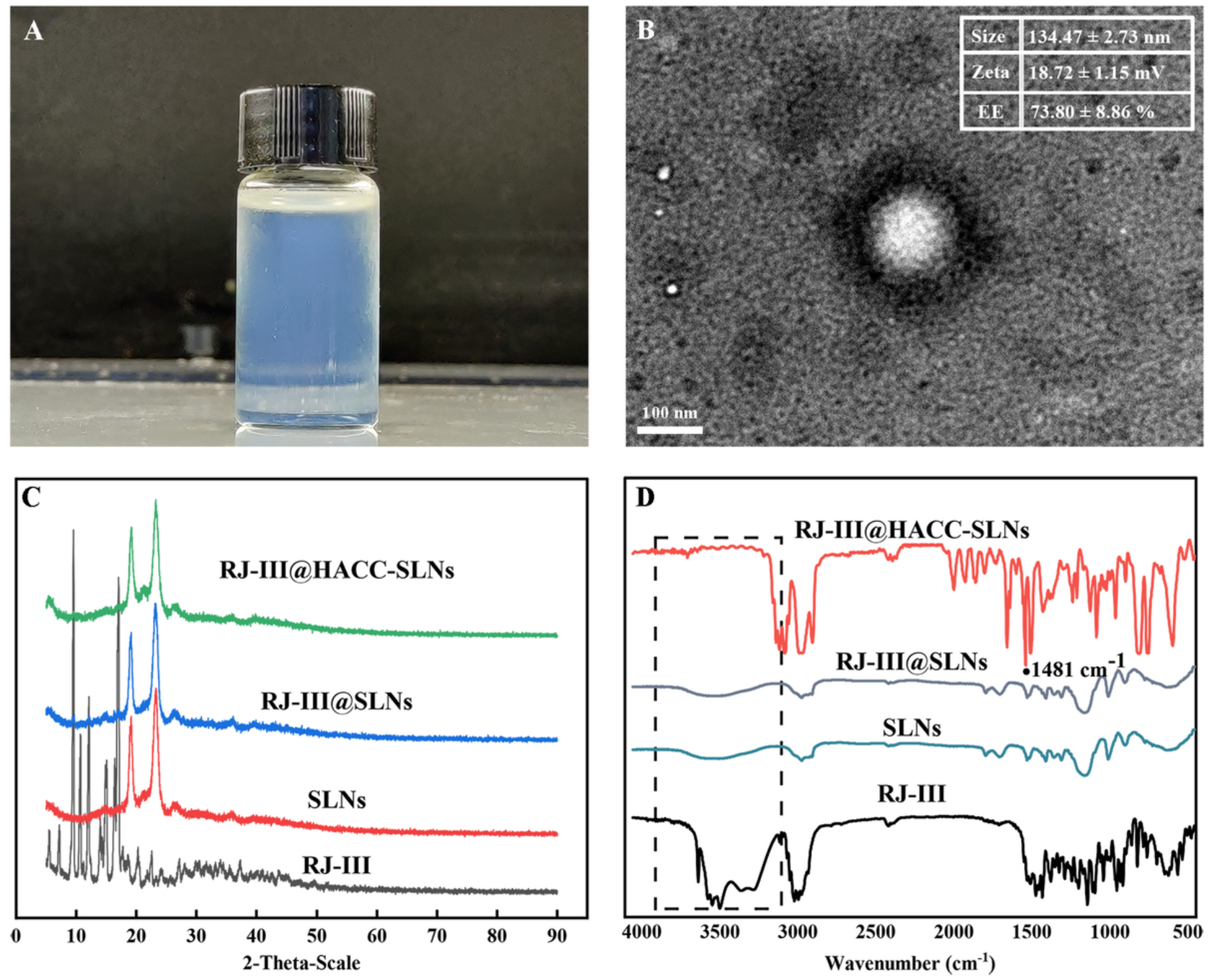

Figure 4

Structural characterization of RJ-II!@HACC-SLNs. (A) The Photograph of RJ-III@HACC-SLNs; (B) TEM of RJ-II!@HACC-SLNs, bar=100 nm; (C) X-ray diffractograms of RJ-III, blank SLNs (SLNs), RJ-III@SLNs, and RJ-III@HACC-SLNs; (D) FT-IR spectra of RJ-III, SLNs, RJ-III@SLNs, and RJ-III@HACC-SLNs. 

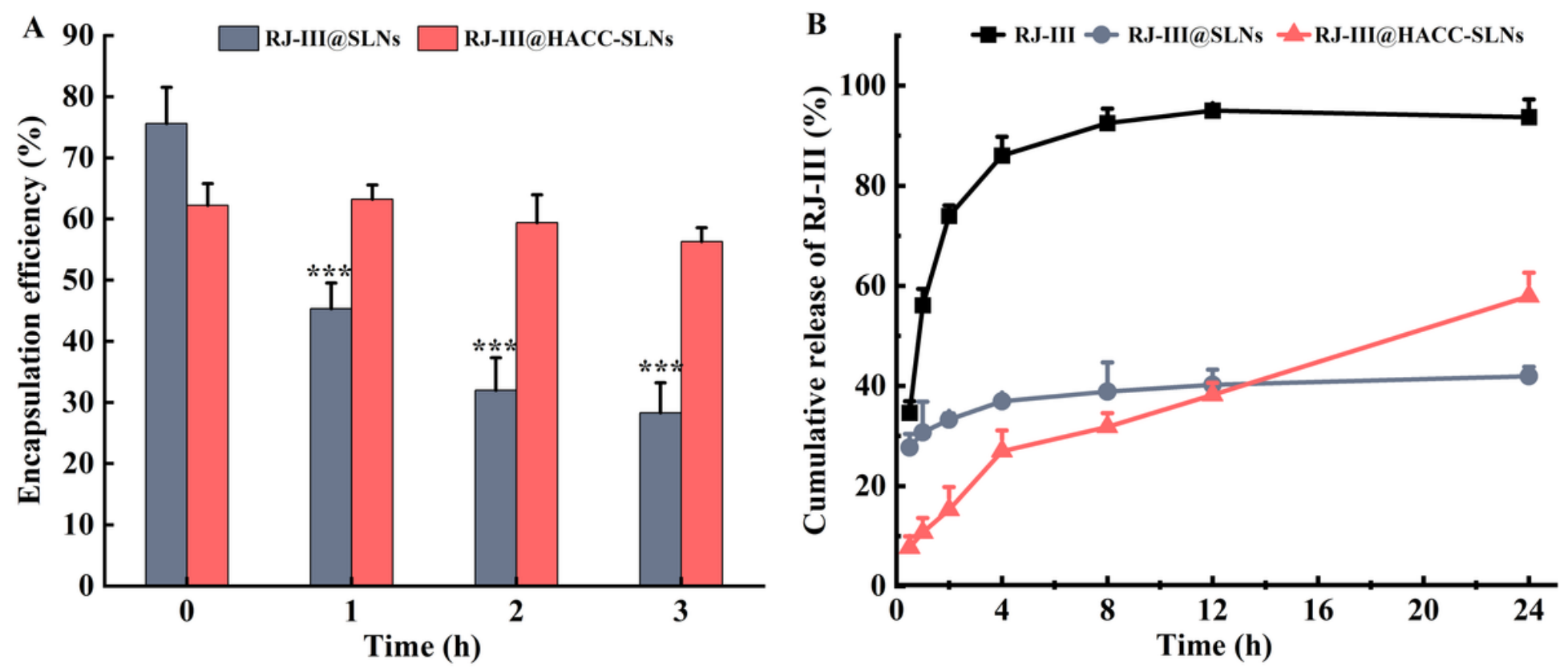

Figure 5

In vitro stability and release profile of RJ-III@HACC-SLNs (Mean $\pm S D, n=3$ ). (A) The stability of RJIII@SLNs and RJ-II!@HACC-SLNs in a simulated gastric fluid. ${ }^{* \star *} \mathrm{p}<0.001$ vs. the EE of RJ-III@SLNs at $0 \mathrm{~h}$. (B) The release profile of RJ-III, RJ-III@SLNs, and RJ-III@HACC-SLNs into PBS at pH 6.8. 


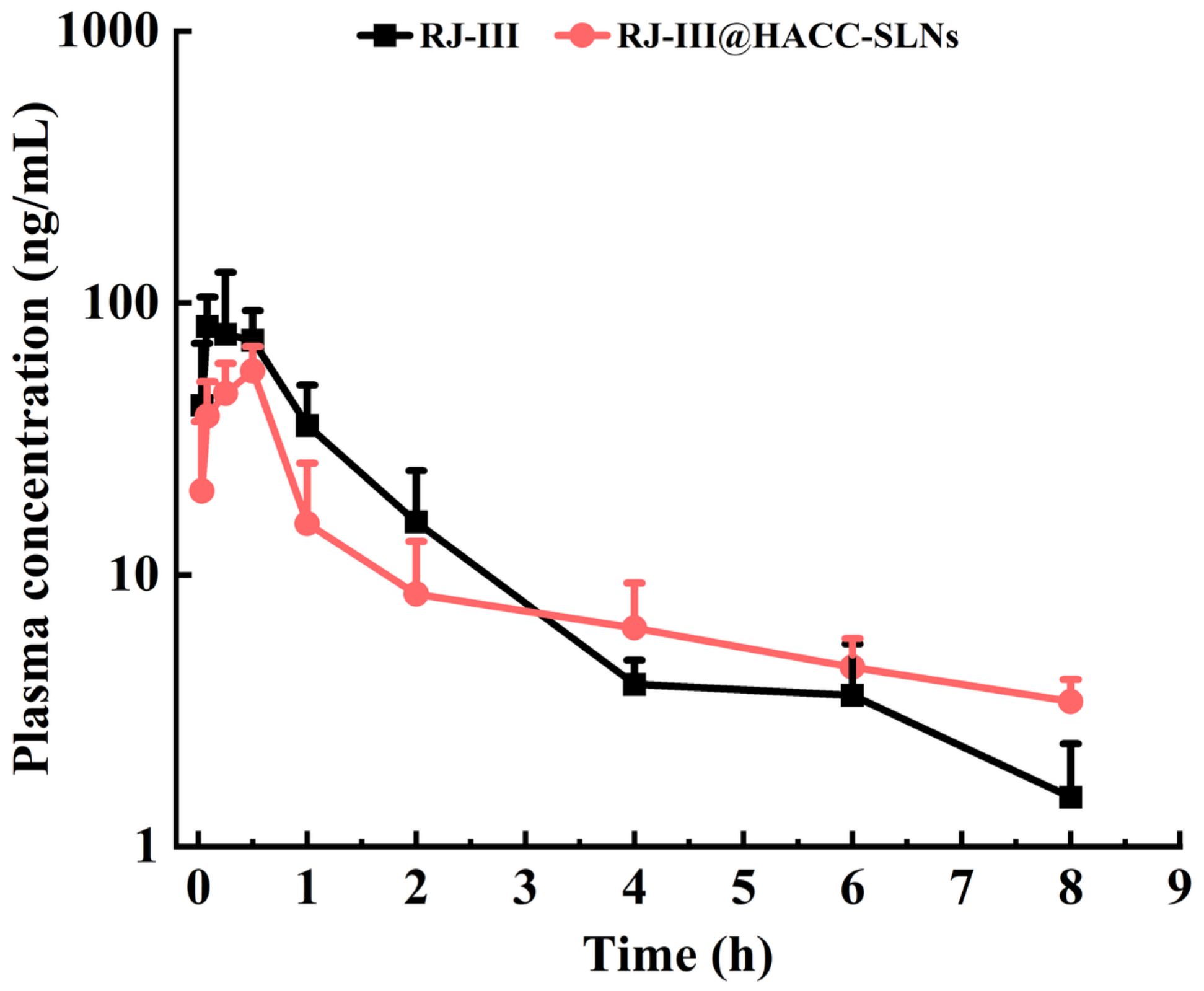

Figure 6

Plasma concentration-time curves of RJ-III after RJ-III and RJ-III@HACC-SLNs (equivalent to $0.2 \mathrm{mg} / \mathrm{kg}$ as RJ-III) were intragastrically administered to mice. (Mean $\pm S D, n=6$ ). 
A

Acetic acid writhing test



C

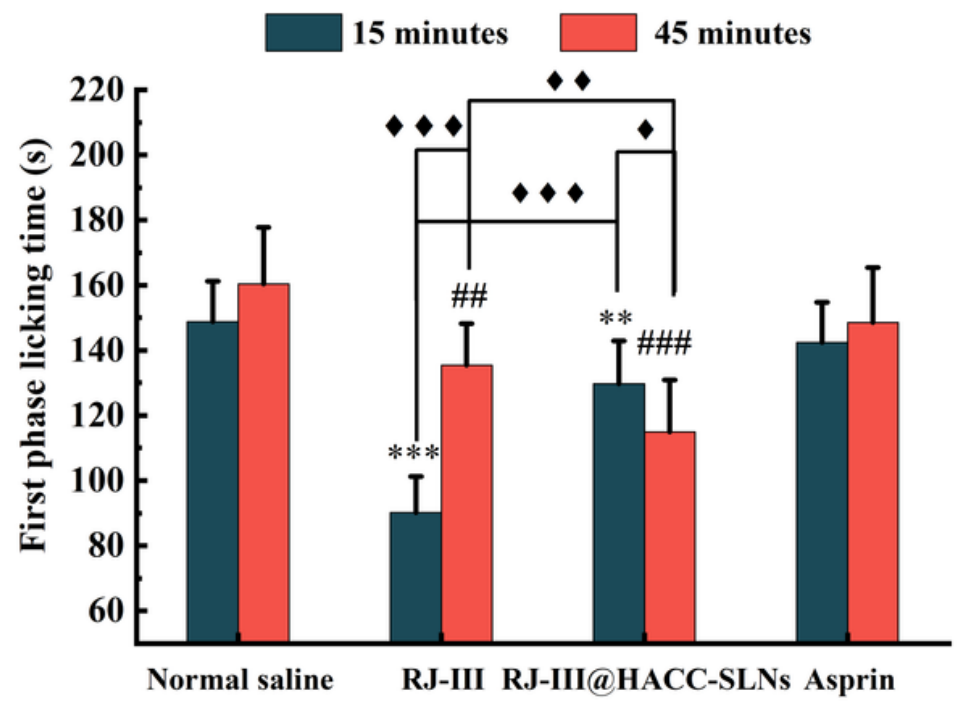

B

Hot plate test

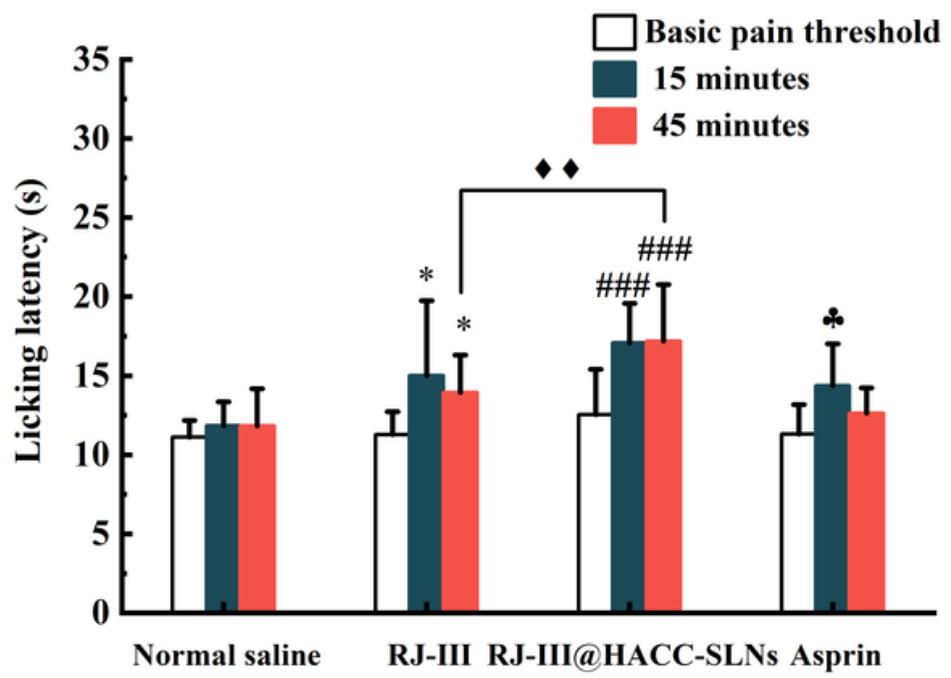

D

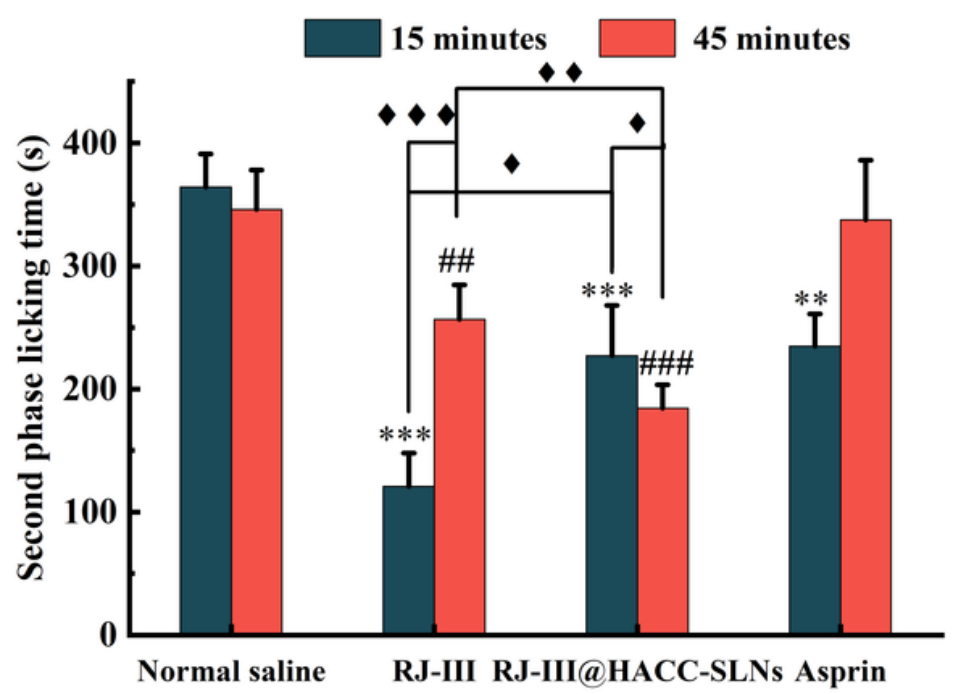

Figure 7

The multimodal analgesia of RJ-III@HACC-SLNs (Mean \pm SD, $n=10$ ). (A) Antinociceptive effects of RJIII@HACC-SLNs in acetic acid-induced writhing test $\left({ }^{\prime} P<0.05 ;{ }^{\cdots \cdots} P<0.01 ;{ }^{\cdots \cdots . . .} P<0.001\right)$. Mice were administered with normal saline (0.9\% NaCl, i.g), RJ-III (0.1 mg/kg, i.g), RJ-III@HACC-SLNs (0.10 mg/kg of RJ-III, i.g), and aspirin (200 mg/kg, i.g). ${ }^{\star \star \star} P<0.001$ vs. normal saline group for administering $15 \mathrm{~min} ;{ }^{\# \# \#} P$ $<0.001$ and ${ }^{\# \#} P<0.01$ vs. normal saline group for administering 45 min. (B) Influence of RJ-III (0.2 mg/kg), RJ-III@HACC-SLNs (0.20 mg/kg of RJ-III), and aspirin in the hot-plate test $\left({ }^{\prime *} P<0.01\right) .{ }^{*} P<0.05$ vs. the basic pain threshold of before administration of RJ-III; \#\#\# $P<0.001$ vs. the basic pain threshold of before administration of RJ-III@HACC-SLNs; $§ P<0.05$ vs. the basic pain threshold of before administration of asprin. (C) and (D) The effects of RJ-III (0.1 mg/kg) and RJ-III@HACC-SLNs (0.10 $\mathrm{mg} / \mathrm{kg}$ of RJ-III) on phases I and II of the formalin test $\left(P<0.05 ;{ }^{\cdots \cdots} P<0.01 ;{ }^{\cdots \cdots} P<0.001\right) .{ }^{\star \star} P<0.01$ and 
${ }^{* * \star} P<0.001$ vs. normal saline group for administering $15 \mathrm{~min}$; ${ }^{\# \# \#} P<0.001$ and ${ }^{\# \#} P<0.01$ vs. normal saline group for administering $45 \mathrm{~min}$.
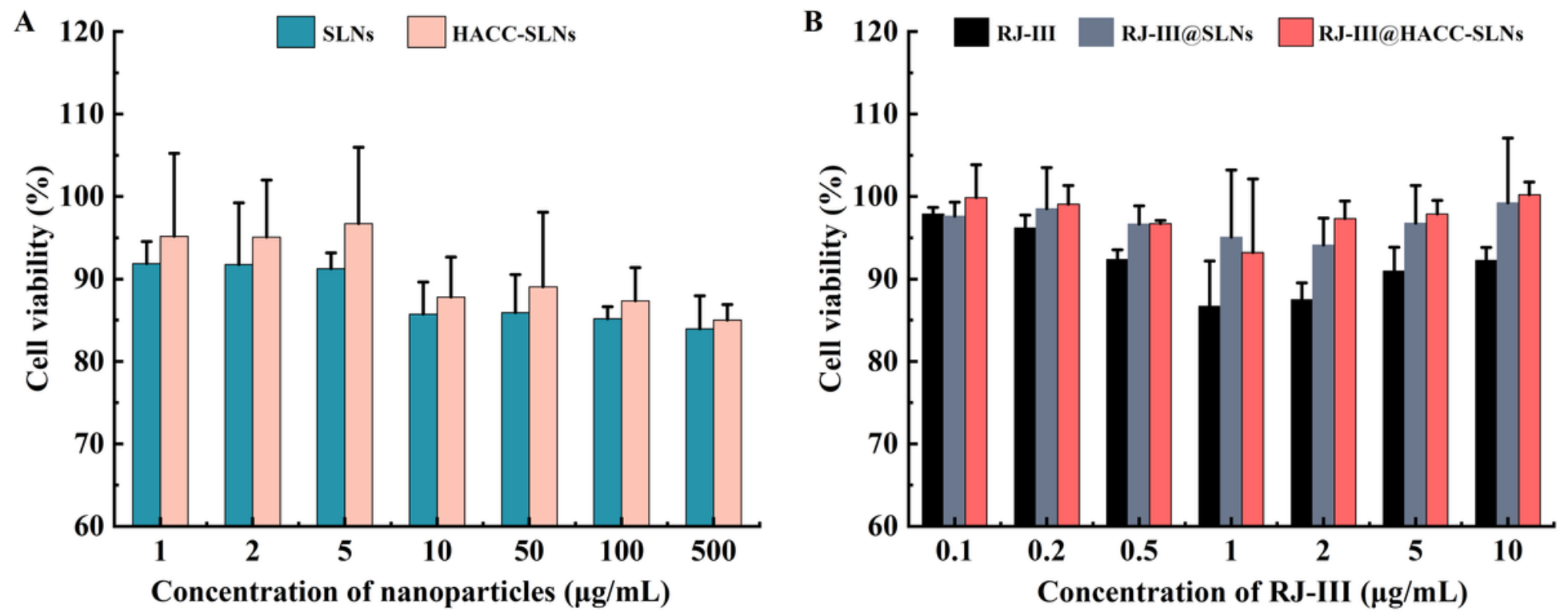

Figure 8

The safety of HACC-RJ-III@SLNs. (A) Cytotoxicity of blank SLNs (B-SLNs) and HACC modified SLNs without RJ-III (HACC-SLNs) in Caco-2 cells after cultured with different SLNs for $24 \mathrm{~h}$ (Mean $\pm S D, n=3$ ).

(B) Cytotoxicity of RJ-III, RJ-III@SLNs, and RJ-III@HACC-SLNs in Caco-2 cells after being cultured with different SLNs for $24 \mathrm{~h}$ (Mean $\pm \mathrm{SD}, \mathrm{n}=3$ ). 


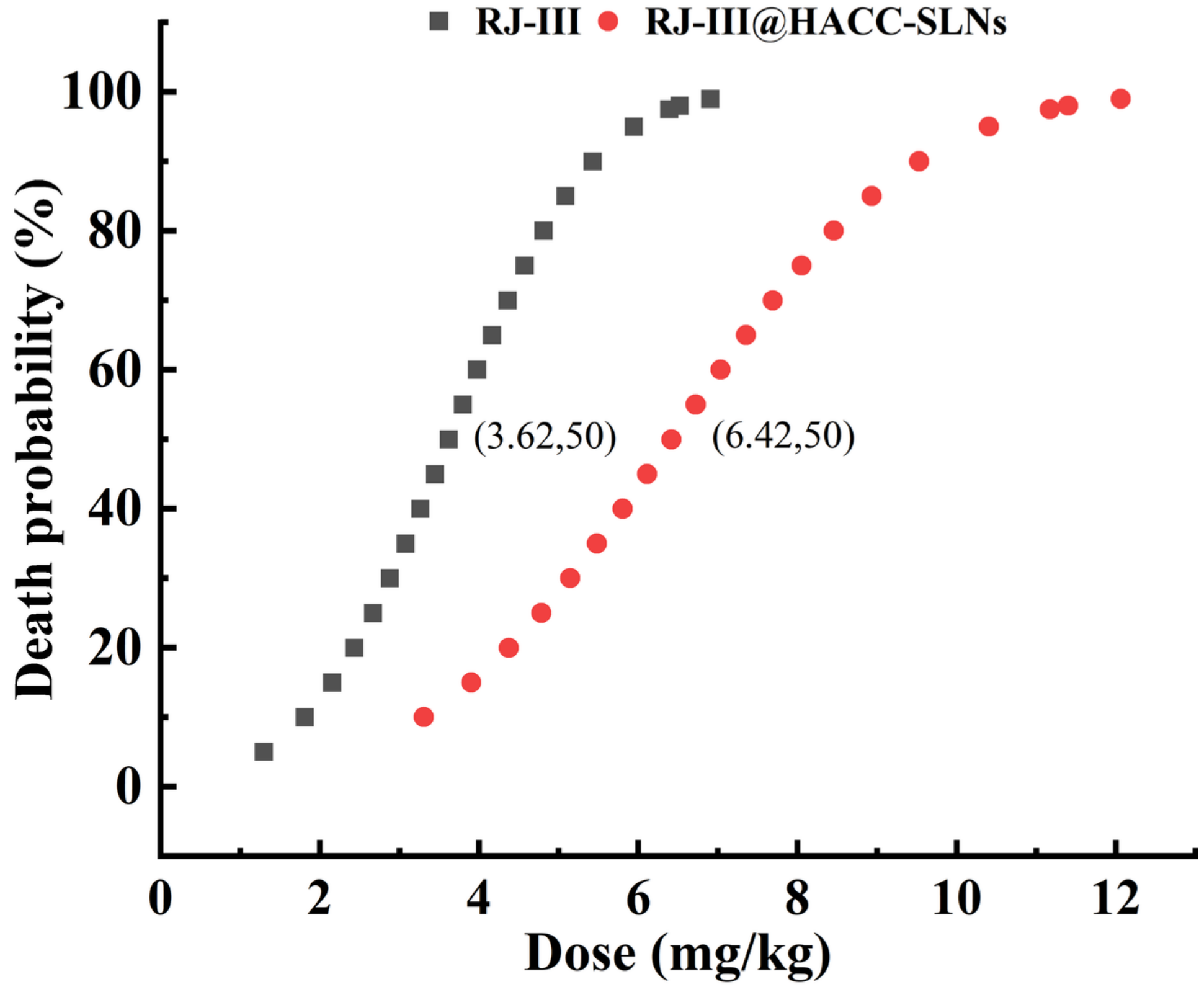

Figure 9

The dosage-mortality curve graph of RJ-III and RJ-III@HACC-SLNs as determined with the Bliss method (n $=8)$.

\section{Supplementary Files}

This is a list of supplementary files associated with this preprint. Click to download.

- graphicalabstract.pdf 